\title{
IMPLEMENTING STUDENT SUCCESS AND SUPPORT PROGRAM SERVICES IN A CALIFORNIA COMMUNITY COLLEGE DISTRICT
}

\author{
A dissertation submitted to the faculty of \\ San. Francisco State University \\ AS \\ 35 \\ 2017 \\ EDD \\ $\cdot S 36$ \\ In partial fulfillment of \\ the requirements for \\ the Degree \\ Doctor of Education
}

In

Educational Leadership

by

Kathleen Claire Schoenecker

San Francisco, California

January 2017 


\section{Copyright by}

Kathleen Claire Schoenecker

2017 


\section{CERTIFICATION OF APPROVAL}

I certify that I have read Implementing Student Success and Support Program Services in a California Community College District by Kathleen Claire Schoenecker, and that in my opinion this work meets the criteria for approving a dissertation submitted in partial fulfillment of the requirement for the degree Doctor of Education in Educational Leadership at San Francisco State University.

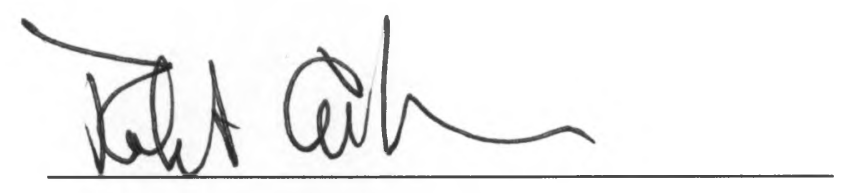

Robert Gabriner, Ed.D.

Professor

Educational Leadership Doctoral Program

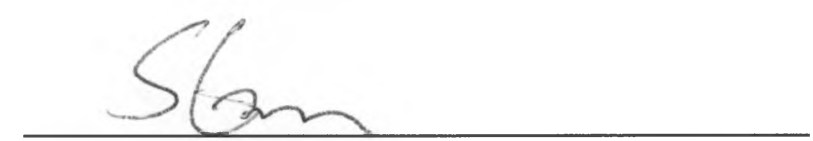

Sheldon Gen, Ph.D.

Associate Professor,

Public Administration

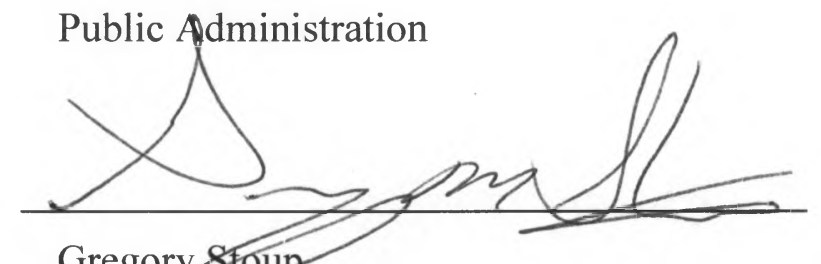

Gregory Sfoup

Senior Dean, Research and Planning, Contra Costa Community College District 


\title{
IMPLEMENTING STUDENT SUCCESS AND SUPPORT PROGRAM SERVICES IN A CALIFORNIA COMMUNITY COLLEGE DISTRICT
}

\author{
Kathleen Claire Schoenecker \\ San Francisco, California \\ 2016
}

California community colleges make higher education accessible for all; however, nearly half its students fail to achieve their goal of degree completion. Based upon the recommendations of the Student Success Task Force, the California legislature passed the Seymour-Campbell Student Success Act of 2012, requiring that all incoming community college students participate in orientation, assessment, and student education planning. This case study examined the impact of these services at the Contra Costa Community College District, and provides the district with recommendations for coordinating and structuring student support services to promote the greatest likelihood for successful student outcomes. Using logistic regression analysis, factors predicting students' completion of a degree, certificate, or transfer-prepared status were identified. Subsequent analyses identified differences in how support services influence completion for students from identified underrepresented groups. Findings revealed that the mandated services of student education planning and counseling services predicted student completion for all groups, as did full-time and continuous enrollment. Findings align with recent changes in how the district provides student support services. The case study provides district leaders with recommendations for allocating resources in a way that fosters student success.

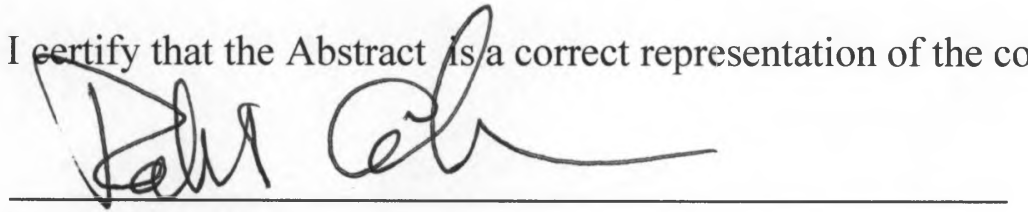

Chair, Dissertation Committee content of this dissertation.

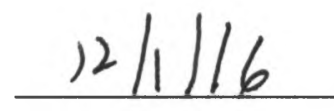

Date 


\section{ACKNOWLEDGEMENTS}

I would not be standing here on the finish line were it not for the guidance, support, patience, and love of so many people. First and foremost, I need to thank my family. Not only have you shown me great patience in the past few years while I worked

through this process, but your lifelong love and nurturing made me the woman who could embark on and achieve this tremendous accomplishment. I want to especially thank my grandfather for being my academic role model and instilling in me a sense of intellectual curiosity from a young age.

I also need to thank my Ohlone colleagues for giving me the encouragement, support, and flexibility I needed to work on this project. Special thanks are due to Shaun and Jim, for their patience when this project took me away from my responsibilities at work, as well as Susan, for her insight on the doctoral process as well as my findings.

Finally, I must thank all of my friends who helped keep me sane through this process. A very special thanks go out to the members of my 2012 cohort, especially my carpool buddies and dissertation Saturday colleagues; your feedback, insight, and support helped make this finished product a reality. 


\section{TABLE OF CONTENTS}

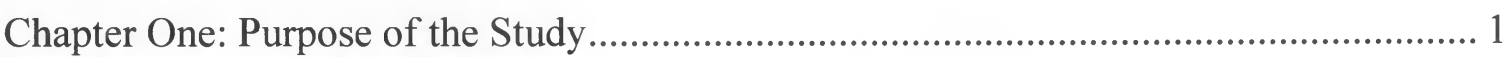

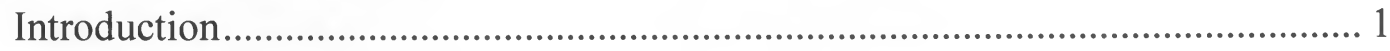

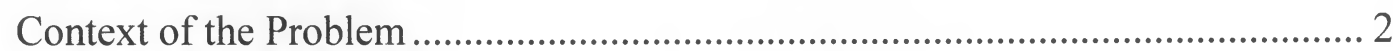

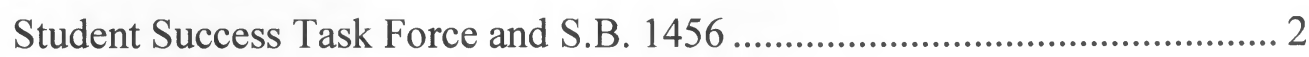

Previous California community college reform efforts ..................................... 4

Student Success Act Implementation................................................................ 6

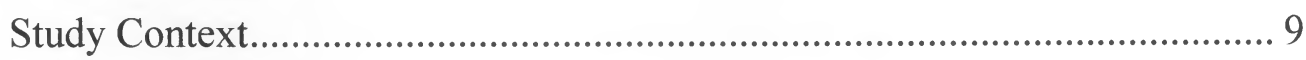

Purpose of the Study ............................................................................................... 10

Research Questions .............................................................................................. 10

Key Constructs and Operational Definitions ......................................................... 11

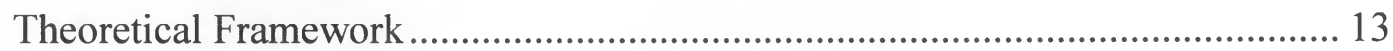

Statement of Delimitations and Scope of the Study ............................................... 14

Significance of the Study ……………............................................................. 15

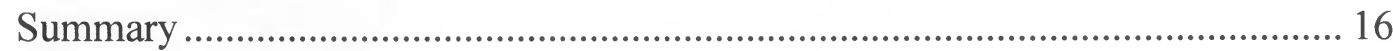

Chapter Two: Literature Review .................................................................................. 17

Services Mandated by the Student Success Act ...................................................... 17

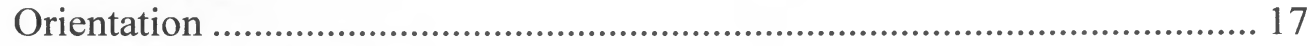

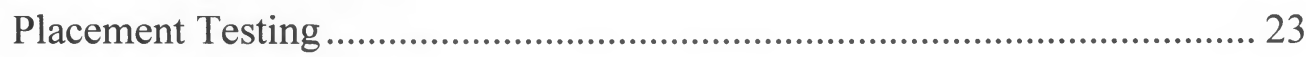

Student Education Plans ............................................................................. 27

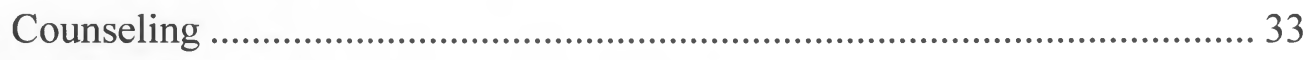

Mandated Services and Underrepresented Students ....................................... 36

Other Factors Related to Student Success .................................................................. 40

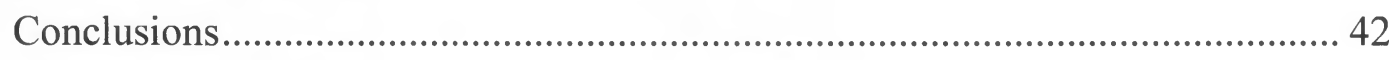

Chapter Three: Methodology ............................................................................................. 44

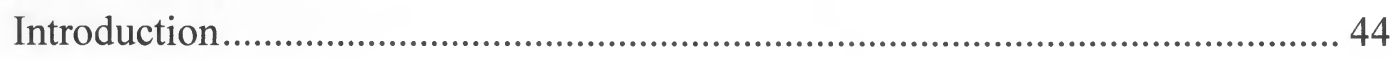




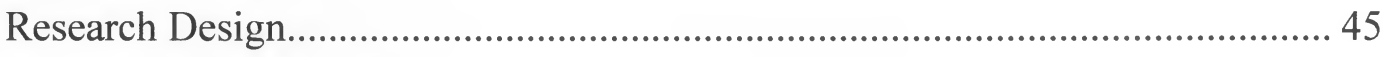

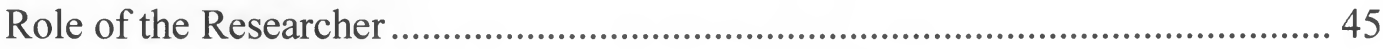

Population, Sample, and Context............................................................................ 46

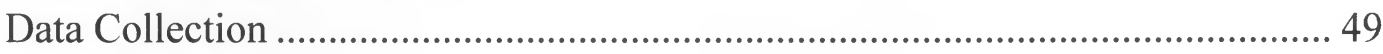

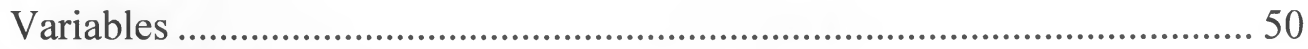

Data Analysis Procedures ..................................................................................... 53

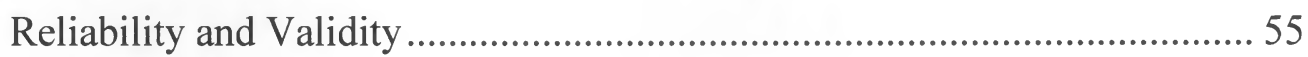

Chapter Four: Report of Findings ................................................................................... 57

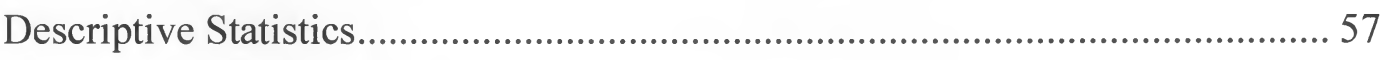

Logistic Regression Analysis................................................................................. 59

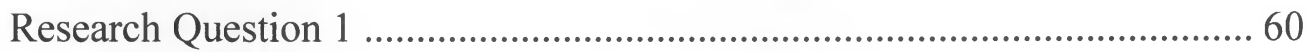

Research Question 2 ..................................................................................... 63

Research Question 3 .................................................................................. 71

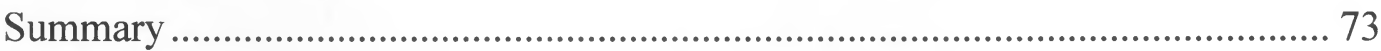

Chapter Five: Discussion and Recommendations.......................................................... 75

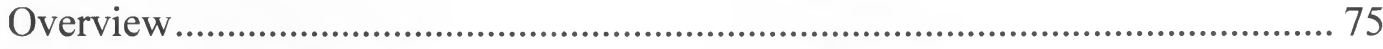

Interpretation of Findings ................................................................................ 76

Universally Significant Findings .............................................................. 76

Narrowly Significant Findings........................................................................ 79

Unexpected Findings ........................................................................................ 81

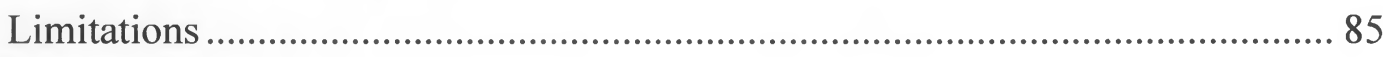

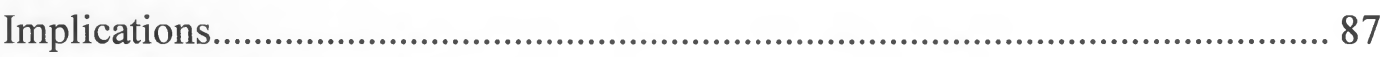

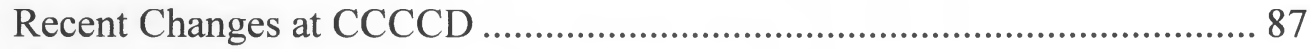

Recommendations for Further Study .................................................................. 89

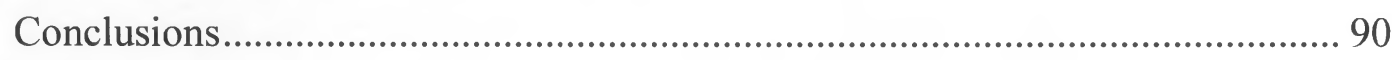

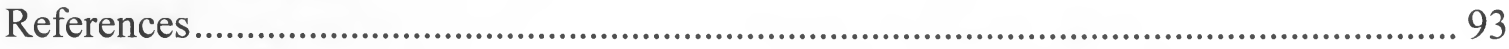




\section{LIST OF TABLES}

Table

Page

3.1 Ethnicity of Sample, by Campus and Overall ........................................ 48

3.2 Financial Aid Status of Sample, by Campus and Overall .......................... 48

4.1 Percentage and Number of Students by Categorical Variable .................... 58

4.2 Means and Standard Deviations on Integer and Ratio Variables ............... 59

4.3 Logistic Regression Analysis Predicting Completion of Educational Goal for

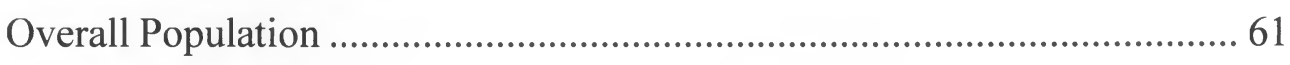

4.4 Logistic Regression Analysis Predicting Completion of Educational Goal, by

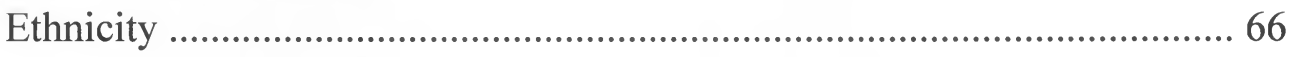

4.5 Logistic Regression Analysis Predicting Completion of Educational Goal, by

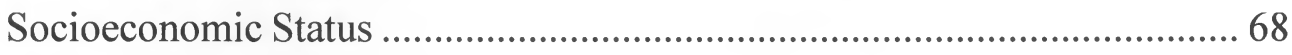

4.6 Logistic Regression Analysis Predicting Completion of Educational Goal, by

Disability Status............................................................................... 70 


\section{Chapter One: Purpose of the Study}

\section{Introduction}

California community colleges enroll over 2.5 million students each year; however, only half of degree-seeking community college students achieve their goal of degree completion (California Community Colleges, Student Success Task Force, 2011). The problem is even worse for students from disadvantaged groups. Among students who began at a California community college in the 2009-10 academic year, 47 percent of students completed a degree, certificate or transferred within 6 years; however, in that same cohort, only 40 percent of Hispanic students and 35 percent of African-American students completed an educational goal. Similarly, the completion rate was only 44 percent for economically disadvantaged students and 38 percent for students with disabilities (California Community Colleges Chancellor's Office, 2016).

In response to this problem, the California Community Colleges Chancellor's Office (CCCCO) convened a Student Success Task Force, to study the problem and develop a strategic plan for improving the success and completion rates of community college students, particularly those from disadvantaged backgrounds. The state's Student Success Act codified several of the task force's recommendations and mandates, including the provision that all incoming California community college students receive the core support services of orientation, placement testing, and a student education plan. In the 2014-15 academic year, colleges began the 
implementation of these mandates under the auspices of the new Student Success and Support Program (SSSP). This case study examined the current state of SSSP service provision at one California community college district.

\section{Context of the Problem}

\section{Student Success Task Force and S.B. 1456}

In 2011, former Chancellor of the California Community College system, Jack Scott, convened a Student Success Task Force to develop a strategic plan for improving success rates among its students, particularly those from disadvantaged backgrounds. The task force included community college professionals, education experts, and representatives from a variety of stakeholder groups. The task force members analyzed policy issues and examined best practices for promoting student success, which they distilled into 22 policy recommendations. Based on a handful of these recommendations, the California legislature passed S.B. 1456, the Seymour-Campbell Student Success Act of 2012, which requires that all incoming community college students participate in orientation, assessment, and student education planning (Seymour-Campbell Student Success Act, 2012, sec. 78210 et seq.). While most of these services are not new - California Community Colleges have been required to offer these services since 1986 - this policy introduced the requirement that students must participate in these services. 
The intent of these new policies is to "help more students to identify their goals and move ahead in their college experience" (California Community Colleges Chancellor's Office, 2012). These policies direct support toward students who attend community colleges with the goal of completing a degree, certificate, or transferring, by providing incentives for students who exhibit "successful behaviors," and ensuring that students have the resources they need to navigate the path toward completing their educational goal (California Community Colleges, Student Success Task Force, 2011). The task force identified that while colleges offer services to support students, they have not had the resources needed to ensure that these services are available to all students. Between this lack of resources and the optional nature of services, too many students have failed to take advantage of these services.

The task force highlighted the fact that a majority of California community college students come from underrepresented groups or disadvantaged backgrounds and these students have disproportionately negative outcomes; as such, the task force was particularly concerned with providing these students the support they need (California Community Colleges, Student Success Task Force, 2011). These mandates went into effect in the 2014-15 academic year, and beginning with the 2015-16 academic year, colleges began receiving supplemental funding for the provision of these services. The supplemental funding is based on a combination of college headcount and the 
percentage of non-exempt students who participate in each service (California Community Colleges Chancellor's Office, 2014).

\section{Previous California community college reform efforts}

The Student Success Act is the California community college system's most recent reform effort to improve student outcomes, but it is not the first. Before the Student Success Act, the last major reform effort was the Basic Skills Initiative (BSI), which began in 2006 . This initiative provided $\$ 33.1$ million in funding for colleges to address basic skills needs and was accompanied by a study of best practices in improving student success. This study, "Basic Skills as a Foundation for Success in California Community Colleges" (Boroch et al., 2007), was meant to inform colleges about how they might spend the money that had been allocated to them. Unfortunately, this initiative included no requirement that colleges spent money in accordance with the best practices and did not formally assess whether or not the funded projects actually improved student outcomes. The only assessments to be conducted were performed by individual institutions on small initiatives that they independently implemented. Aside from modest improvements in students' basic skills course completion and improvement rates (Academic Senate for California Community Colleges, 2010), little data exists regarding the effectiveness of this initiative in improving the success rates of students in basic skills courses. As a result, it is questionable whether the millions of dollars spent on this initiative had a worthwhile effect. 
Before the BSI, the Seymour-Campbell Matriculation Act of 1986 was the first major initiative in the California Community Colleges to focus on student success, not just access. This initiative was the first to require that colleges provide orientation, placement testing, and counseling services to students. Unfortunately, two major issues stymied the effectiveness of this initiative. First, the initiative never received the full funding promised by the legislature, which meant that colleges were unable to provide enough services to ensure that all students had the opportunity to participate in them (California Community Colleges, Student Success Task Force, 2011). During California's fiscal crisis in 2009, the 2009-10 state budget significantly reduced California's education funding, and introduced a provision whereby colleges could choose to reallocate the money from several of their categorical programs to other categorical programs in whatever way the college saw fit. The matriculation program was one of the programs that could have its money reallocated, and many colleges took advantage of this opportunity, leaving matriculation programs even further underfunded. Additionally, the matriculation initiative did not require students to participate in these services; it only required colleges to offer them, and only to the extent that funding was available. Because of these factors, the rates at which colleges offered and students participated in these services varied widely. Furthermore, the effectiveness of this initiative was never assessed, so the impact of the initiative is unknown. 
In summary, the California Community College system has made two prior attempts to address the issue of low student achievement rates through policy reform. Unfortunately, the problem continues to persist today, which was the impetus for the Student Success Act.

\section{Student Success Act Implementation}

Over twenty-five years later, the Seymour-Campbell Matriculation Act of 1986 was rewritten as the Seymour-Campbell Student Success Act of 2012. In addition to implementing a handful of the recommendations of the Student Success Task Force, the Student Success Act is an attempt to pick up where the Matriculation Act left off, by not just requiring colleges to make student support services available to students, but requiring students to participate in these services. Furthermore, unlike the Matriculation Act, which never received the full funding necessary for its implementation, the state of California dedicated millions of dollars for colleges to implement the Student Success Act mandates: approximately $\$ 75$ million in the 2013-14 year, over $\$ 173$ million for the 2014-15 year, and over \$266 million for the 2015-16 year (California Community Colleges Chancellor's Office, 2015). In these ways, the Student Success Act seems to be a better-developed policy than the Matriculation Act.

Another shortcoming of the BSI and the Matriculation Act is that neither of these initiatives included an assessment component to determine whether the initiatives were accomplishing the goals they set out to achieve. The Student Success Act takes a 
step toward incorporating the assessment of student outcomes by requiring that colleges receiving SSSP funding must implement the new Student Success Scorecard; a set of accountability metrics developed to rate a college's performance. While college participation in accountability and outcomes reporting is not a new requirement, the Student Success Act changed the specific format of the report to include updated and more meaningful metrics and disaggregated results by demographic group. As such, the Student Success Act places a greater emphasis on assessment of outcomes than prior reform efforts. However, the Student Success Scorecard is not without limitations. First, the scorecard metrics are broad outcome metrics reported for the college, as a percentage of students who met the outcome. These outcomes include completion of 30 units; completion of more than 8 units of career technical education; completion of a basic skills sequence; persistence through the first 3 consecutive terms; or completion of a degree, certificate, or transfer. Because these metrics are so broad, it is hard to use the scorecard results as an assessment tool to measure any particular intervention or initiative. Instead, the scorecard is more of a barometer for a college's overall achievement. Second, the scorecard uses cohort analysis to track the identified metrics; the identified cohort consists of first time students, with a reported social security number, whose course-taking patterns exhibit behavior intent to complete a degree or transfer. Unfortunately, the profile of the cohort defined for use with the scorecard is so narrow, that it represents only 8.3 percent of the students enrolled in the California 
community college system in a given year (California Community Colleges

Chancellor's Office, Research, Analysis and Accountability Unit, Technology, Research and Information Systems Division, 2013). For these reasons, the Student Success Scorecard should be regarded as more of an accountability report card than a true assessment tool.

Because of the Student Success Act's connections to outcomes assessment, districts ought to be concerned with how the SSSP mandated services influence student outcomes. While the Student Success Task Force endorsed orientation, placement testing, and student education plans as positively affecting student outcomes, questions remain about the extent to which these services impact outcomes, and whether some services have a greater impact on outcomes than others. Furthermore, the Student Success Scorecard is limited in that it is mostly an accountability report card for districts to track their student outcomes. It does not directly link student participation in services to student outcomes. Districts who want to improve their scorecard metrics may lack the resources to identify the relationships between services and student outcomes. While colleges are required to ensure that students participate in all of the mandated services, colleges can choose to coordinate service provision as they see fit to best meet the needs of their students. This can involve dedicating more resources and staff time to the most impactful services and streamlining or automating the provision 
of less impactful services. As such, there is a need for districts to identify how SSSP mandated services influence students' educational outcomes.

\section{Study Context}

This study examines a cohort of community college students who enrolled in the Contra Costa Community College District (CCCCD) for the first time in the 2008-09 academic year. The CCCCD is a three-college district in the San Francisco Bay area, serving nearly the entire area of Contra Costa County. The largest ethnic groups served by the district are White (31\%), Hispanic (26\%), and African-American (13\%), but the demographic profiles of the three colleges are very different. Contra Costa College (CCC) is in an industrial urban area, serving approximately 12,000 students each year, most of whom are African-American and Hispanic, and 32 percent of whom receive some form of financial aid. Diablo Valley College (DVC) is the largest of the colleges and is located in an affluent suburban area, serving approximately 29,000 students each year, 17 percent of whom receive financial aid. Nearly half of its students are White, but it has a growing Hispanic population. Los Medanos College (LMC) is the newest of the colleges and is located in a historically rural agricultural area that has grown into a suburban community. It serves approximately 13,000 students each year, 27 percent of whom receive some form of financial aid; the largest group is Hispanic students, but there are also large White and African-American populations. 
The CCCCD greatly values issues of equity and social justice. This commitment is reflected in the core values, mission, and strategic goals of not just the district but the three individual colleges as well. Several strategic goals of both the district and the colleges address the need to provide educational environments and support services that are responsive and sensitive to the unique needs of their diverse population.

\section{Purpose of the Study}

The purpose of this study was to examine the provision of the services mandated by the Student Success Act in the CCCCD. While student participation in these services became required in the 2014-15 academic year, districts have been offering most of these services for nearly two decades. This retrospective case study will examine student participation in these services to identify what kind of relationship exists between these mandated services and students' educational outcomes at this district. Because the members of the Student Success Task Force were particularly concerned with the success of underrepresented and disadvantaged students, this study also examines the impact of the SSSP mandated services on students in a handful of these groups. The findings of this case study can help practitioners and leaders of the CCCCD to plan the implementation of SSSP services in a way that fosters better outcomes for their students.

\section{Research Questions}


This quantitative study investigated the current provision of SSSP mandated services at the CCCCD. The purpose of this study was to identify the extent to which SSSP mandated services predict students' educational outcomes, including completion of a degree or certificate, or attainment of transfer-prepared status. Additionally, this study seeks to identify differences in how these mandated services influence the educational outcomes of students in identified underrepresented groups. The research questions driving this study were:

1. Which of the support services mandated by the Student Success Act are most predictive of successful outcomes for students in the Contra Costa Community College District (CCCCD)?

2. How do the relationships between students' utilization of support services and their educational outcomes differ among students from identified underrepresented backgrounds (Hispanic, African-American, low socioeconomic status, disabled)?

3. Is there a pattern or combination of services that is more likely to lead to successful outcomes for students from certain underserved groups (Hispanic, African-American, low socioeconomic status, disabled)?

\section{Key Constructs and Operational Definitions}

Mandated services. The support services of orientation, assessment, and student education planning, which the Student Success Act requires community 
colleges to provide to all incoming students. Colleges provide these services under the auspices of the Student Success and Support Program (SSSP).

Assessment. The process of identifying which level of math or English classes a student qualifies for, typically based on the results of an assessment test. Assessment is one of the SSSP mandated services. For the purposes of this study, the terms "assessment" and "placement" are synonymous.

Student Education Plan (SEP). A term-by-term outline of all of the courses a student must take in order to achieve his or her educational goal, including all general education, major and prerequisite courses. Receipt of an SEP is one of the SSSP mandated services. Initial or abbreviated SEPs are a new concept introduced by the Student Success Act; they provide students with an abbreviated version of the comprehensive SEPs examined in this study and advise students on their first few semesters before they finalize their educational goal. However, because this secondary distinction had not yet been established during the time frame of this study, the term SEP in this study refers to a comprehensive SEP.

Basic skills. Courses designated as "below transfer-level" in math, English, or English as a second language (ESL). Students who place into or attempt one or more basic skills classes are designated as basic skills students. A basic skills sequence is a series of sequential basic skills courses that culminates in a college-level course. For the purposes of this study, the terms "basic skills" and "remedial skills" are synonymous. 
Success. Students' progress toward or completion of their educational goal. A handful of success metrics have been defined by the California Community Colleges Chancellor's Office, including completion of one's educational goal (degree, certificate, or transfer preparation), completion of 30 degree-applicable units, or completion of a basic skills sequence, including the successful completion of a college-level course in the relevant subject.

Completion. Achievement of a student's educational goal, which includes earning either a certificate or degree, transferring to a four-year institution, or attaining "transfer prepared" status, which is the completion of $60 \mathrm{UC} / \mathrm{CSU}$ transferable units with at least a 2.0 grade point average.

\section{Theoretical Framework}

Vincent Tinto's (1975) seminal work on student integration has informed much of the research on college student development in the past 40 years. This model theorizes that students' persistence and graduation is a function of their social integration into the college community. While a number of factors can influence this integration, institutions can foster students' commitment to and integration with the college by reaching students early and providing programs and services to help facilitate a smooth transition into the institution. In fact, Tinto summarized the purpose of these services in a 1999 article on services in the first year of college: 
Students are more likely to persist and graduate in settings that provide clear and consistent information about institutional requirements. Students need to understand the road map to completion and know how to use it to decide upon and achieve personal goals. (Tinto, 1999)

The Student Success Act reflects this concept in the type of services it mandates for incoming students. The purpose of orientation is to provide "information about institutional requirements." The student education plan is a student's "roadmap to completion," which incorporates both a student's educational goal, as well as any remedial courses identified by the results of their placement test. This study draws upon the work of Tinto and as well as others who have applied Tinto's theories to community college students (Borglum \& Kubala, 2000; Deil-Amen, 2011; Halpin, 1990; Shepler \& Woosley, 2012; Stuart, Rios-Aguilar, \& Deil-Amen, 2014) and student support services (Pascarella, Terenzini, \& Wolfle, 1986).

\section{Statement of Delimitations and Scope of the Study}

This case study examined the provision of SSSP mandated services at one California community college district. As such, the practitioners and administrators at this district are the primary audience for the findings of this study, and claims of the generalizability of the results of this study will be limited to similar students within the CCCCD. To a limited extent, some findings may be relevant for practitioners at colleges with similar profiles. 


\section{Significance of the Study}

The goal of this dissertation study is to inform leaders and practitioners from the CCCCD about the effectiveness of services to support community college students in their district, particularly regarding the support services mandated by the Student Success Act. Since community colleges are still in the first few years of implementing SSSP mandated services, the findings of this study may provide evidence about more effective ways to coordinate and implement these services.

Additionally, the findings may provide community college practitioners with more effective ways of supporting students, including students from diverse populations. Part of the justification of the Student Success Act is that while the mandated services are beneficial for students, not all students are aware of these benefits. As a result, many students, especially those who are unfamiliar with the college environment, choose not to take advantage of them. One theory behind the Student Success Act is that by requiring all students to participate in these services, nontraditional or underserved populations will be able to take advantage of the same

services as their majority peers. Since this emphasis on equity is one of the goals of the Student Success Act, there is a need to validate this assumption that directing underserved students to these mandated services will lead to a greater likelihood of successful outcomes for these students. 


\section{Summary}

California community colleges have always focused on making higher education accessible for all. Consequently, they enroll more than half of California's college students and serve an incredibly diverse population. However, given the poor outcomes of the majority of community college students, the time has come to focus on efforts to improve student outcomes in colleges. The services mandated by the Student Success Act are an effort to improve student outcomes, but they are not the first such effort. Past reform efforts have failed, in part due to a lack of resources and a lack of accountability measures. The Student Success Act also uniquely focuses on not just improving the success rates of community college students in general, but improving these success rates across student groups so that students from underrepresented and disadvantaged groups have outcomes comparable to their majority peers. The purpose of this study is to examine the impact of these mandated services at one community college district, the Contra Costa Community College District, and provide recommendations for that district on how its student support services can be coordinated and structured in a way that promotes the greatest likelihood of successful outcomes for its students. 


\section{Chapter Two: Literature Review}

\section{Services Mandated by the Student Success Act}

Given the state's emphasis on the mandated services of orientation, placement testing, and student education plans, the extant research on the effectiveness of these services in increasing students' success and completion leaves much to be desired. Of the published literature regarding the impact of these three services, nearly all studies have examined the effects of each service in isolation, with little regard for the combined effects of receiving multiple services.

\section{Orientation}

Orientation has been a staple of the college matriculation process for decades. The purpose and importance of orientation was best articulated by Tinto (1987), who said “An institution's capacity to retain students is directly related to its ability to reach out and make contact with students and integrate them into the social and intellectual fabric of institutional life" (p. 180). Building on Tinto's theory, Pascarella, Terenzini, and Wolfle (1986) conducted some of the earliest research on the impact of college orientation on student persistence. Their definition of orientation, which has been cited in subsequent orientation studies, is an activity "designed both to increase the student's knowledge of the institution and its traditions and to facilitate his or her integration into the institution's social and academic systems" (p. 156). In contrast to this holistic and multifaceted conceptualization of orientation, the California Education Code defines 
orientation as the provision of eight categories of information related to the policies and procedures of the college:

“(1) Academic expectations and progress and probation standards ... (2)

Maintaining registration priority ... (3) Prerequisite or co-requisite challenge

process ... (4) Maintaining Board of Governors Fee Waiver eligibility ... (5)

Description of available programs, support services, financial aid assistance, and campus facilities ... (6) Academic calendar and important timelines, (7)

Registration and college fees, (8) Available education planning services." (5

CCR $\S 55521)$

The limited definition provided by the California Education Code leaves room for colleges to implement the orientation requirement in whatever format they see fit to best meet the needs of their students. The colleges in the CCCCD use this definition to provide orientation services to students; however, they offer orientation in a few different formats to meet students' needs. Orientation services are specific to the individual college the student is planning to attend, so the information varies slightly to account for differences in available services and college-specific policies. However, the information covered is comparable, since all orientation sessions conform to the definition set forth in Title V.

Most incoming students are directed toward a traditional orientation workshop, which is a two-to-three-hour presentation led by a counselor. The presentation is in a 
lecture format and provides students with all of the information outlined in Title V (Jeffrey Benford, personal communication, October 6, 2016). Additionally, students may opt to participate in an online version of the orientation, which presents the same information as the in-person orientation session, but delivered through an online content management system.

For students who are seniors at a local high school and are planning to attend one of the colleges in the fall after graduation, the colleges hold an event called "Super Saturday" to orient students to the college. Students attending Super Saturday are broken into groups of approximately 40 students for a standard three-hour orientation presentation, led by a counselor. The day's events also include presentations for parents as well as campus tours and introductions to the various activities students can participate in once enrolled at the college.

There are a number of challenges in comparing the orientation provided at CCCCD to orientation as described in the literature. Much of the literature that uses the term "orientation" actually refers to either an orientation program conducted over several days (Pascarella et al., 1986; Perrine \& Spain, 2008) or a full-term student success course for freshman, such as those offered in first year experience programs (Derby \& Smith, 2004; Derby, 2007; Fowler \& Boylan, 2010; Mayo, 2013; Nguyen, Hays, \& Wetstein, 2010). All of these studies all found that participating in these activities resulted in positive effects, such as higher persistence rates (Derby \& Smith, 
2004; Nguyen et al., 2010), higher GPAs (Fowler \& Boylan, 2010), and higher rates of degree completion (Derby, 2007; Derby \& Smith, 2004). However, one should interpret these findings cautiously, since these activities are more comprehensive than the orientation services provided by the CCCCD colleges. For example, even the longest orientation sessions that $\mathrm{CCCCD}$ provides are only four hours long, as opposed to the day or weekend long events described in much of the literature. Venezia, Bracco, and Nodine (2010) corroborate this with their finding that "most [community college] students believe that matriculation services are a one-shot deal—something that happens over the course of one day and is never revisited" (p. 2).

One possible explanation for the positive effects of the longer orientation events comes from Pascarella, Terenzini, and Wolfle's (1986) study of the impact of orientation attendance on student persistence. This study was grounded in Tinto's (1975) theory that students' persistence and success is largely a function of how academically and socially integrated they are into the college environment. Their findings indicate that the positive effects of orientation are associated with how well the institution uses it to integrate students into the college community. As such, it is likely that the positive benefits of these types of orientations may have more to do with the fact that these services are offered over a longer period of time, allowing students to accrue social benefits. Since it is unlikely that such integration can be developed in a brief workshop, let alone online, this is a possible explanation for the differential impact 
of extended orientations as compared to the brief orientations provided by California Community Colleges.

A handful of studies use the same or a similar definition of orientation as that used by California Community Colleges; therefore, these studies provide helpful conclusions regarding the impact of orientation attendance on student success. Shulock and Moore (2007) examined factors that influence California community college students' completion of a degree or certificate and found that students who attended an orientation were slightly more likely to complete a degree than students who did not participate in orientation. Similarly, Ellis-O’Quinn (2012) found that attending an orientation session had no impact on student persistence, but that there was a correlation between orientation attendance and subsequent grade point average. Hollins (2009) conducted a study that provides a useful comparison of the impact of a brief orientation workshop to a longer student success course for community college students. This study used chi-squared analysis to compare students who participated in a half-day orientation to non-oriented new students. Additional analyses compared non-oriented students to a subset of orientation participants who also enrolled in and completed a college success course in their first semester. While students who participated in orientation had slightly higher GPAs and higher persistence rates than students who did not participate in orientation, both of these measures were even higher for students who attended 
orientation and subsequently completed the college success course. However, it is worth noting that only the differences in persistence rates were statistically significant.

Jaggars and Fletcher (2014) conducted a case study of one community college's redesign of its student intake process, much of which focused on its orientation program, which has an online component followed by an in-person meeting with a counselor. What makes this study particularly relevant is that the community college's intake process is very similar to the model of matriculation services for incoming students prescribed by the Student Success Act in that it includes mandated orientation, placement testing, and an initial appointment with a counselor to select classes. The fact that the study's orientation is online is also a helpful comparison to the CCCCD, who offered online orientation as an option at the time of this study and has since moved the majority of its orientation services online. Before the redesign, students reported that the online orientation session provided little, if any, relevant information and was missing much of the information that was important to them, such as information about academic programs or transfer (Jaggars \& Fletcher, 2014). Similarly, counselors and academic advisors described the original orientation program as covering an overwhelming amount of information and reported that in-person interactions with students suggested that most students had "obviously ignored the content" (p. 7). After the redesign process, which included developing new and modifying old systems of finding information, orientations began to include training for students on how to utilize 
these tools effectively in order to navigate their educational journey more independently. While this study did not assess the longer-term impact of the orientation redesign, it does serve as a pertinent example of how community colleges can take up the issue of tailoring their orientation and intake procedures to best meet students' needs.

The take-away from the extant literature on orientation is that integration into the college community has a positive impact on students' educational experiences, and orientation is a vehicle that colleges and universities use to facilitate this integration. However, the extent to which the form of orientation provided by California community colleges actually achieves this objective is not well-established by the literature.

\section{Placement Testing}

The Student Success Task Force identified the issue of preparedness for collegelevel work as a significant barrier to success for community college students; they cite that more than 70 percent of California community college students require some form of remedial coursework (California Community Colleges, Student Success Task Force, 2011). As such, appropriate support for community college students must include instruction to help prepare students for college-level work. In order to ensure that students receive instruction that is appropriate for their achievement level, institutions offer placement testing to determine incoming students' students' level of preparedness 
for college-level math and English. Similar to orientation, placement testing is not a new service; what is new is the requirement that all students participate in it.

Each of the colleges in the CCCCD offer placement testing and require an appropriate placement test score to enroll in all but the lowest levels of English, ESL, and math classes. However, each of the colleges uses a different placement test and have different policies around placement testing.

Extant research on the effectiveness of such placement tests in accurately assessing students' achievement and placing them into appropriate courses is mixed. In their study of the relationship between math placement testing and subsequent grades in a math course, Rueda and Sokolowski (2004) found that students who took the placement test and enrolled in the recommended course were more likely to pass their math course than students who did not take the placement test or enrolled in a higher course than recommended. However, a growing body of research has suggested that placement test scores are not always the most accurate predictor of students' success in future courses. Medhanie, Dupuis, LeBeau, Harwell, and Post (Medhanie, Dupuis, LeBeau, Harwell, \& Post, 2012) examined the relationship between students' scores on the ACCUPLACER placement test and their subsequent performance in their first college math course and found that ACCUPLACER scores had no statistically significant effect on the students' likelihood of passing their math course. Belfield and Crosta (2012) added to this argument with their analysis of the correlation between 
scores on two common college placement tests (ACCUPLACER and COMPASS) and students' college performance. They found that the ACCUPLACER and COMPASS had similarly weak correlations with students' GPA, credit accumulation, and successful completion of developmental courses across all subject areas. Furthermore, their analysis found that students' high school GPA correlated significantly better with the same measures of college performance and was a more consistent predictor across subjects.

Two recent studies have built upon this correlational research to examine the impact of using high school GPA in the process of assessing students and placing them into college courses. Denny, Nelson, and Zhao (2012) studied one college's experiment to combine students' high school grade point average with their placement test score to create a new metric for determining students' math course placement. Their analysis of the impact of this college's policy found that students who were placed by the new metric were more likely to pass and less likely to withdraw from their math course than students whose placement was based on their placement test score alone. Similarly, Ngo and Kwon (2015) specifically studied the use of high school GPA as a placement method through their experimental comparison of students who placed into math courses by placement test alone with those students who were placed into the same courses using a "multiple measures boost" (p. 444). According to this placement policy, students could earn extra points to add to their raw test score for factors such as high 
school GPA and previous math courses taken (p. 450). The researchers found that the two groups of students had the same rates of successful course completion.

Furthermore, follow-up analysis of students impacted by the multiple measures boost found that this policy led to an increased number of underrepresented minority students gaining access to higher-level math courses.

This concept of utilizing multiple measures of student achievement to place students more accurately continues to gain attention, in part due to this growing body of research questioning the validity of placement tests. While California's matriculation requirements have included a provision that placement should be based on multiple measures since their enactment in 1986 (Seymour-Campbell Matriculation Act, 1986, sec. 78210 et seq.), most college placement procedures do not incorporate alternate measures of student achievement in a meaningful way. Most colleges still use standardized placement test scores as their primary form of assessment, including the three colleges in the CCCCD. At the time of this study, only DVC offered an "Informed Self-Assessment" option for students who tested below college level math. However, this assessment was optional and used by fewer than $2 \%$ of students in this sample who took a math placement test. Since the Student Success Task Force specifically mentioned multiple measures assessment in one of its recommendations regarding placement testing, there have been recent efforts by the California Community College system to revise placement practices in a way that meaningfully incorporate multiple 
measures, specifically including students high school grade point average. Practitioners should pay close attention to the implementation of multiple measures assessment in coming years.

Such mixed findings regarding the importance of placement tests to students' success suggest the need for additional research in this area. This is especially important to consider in light of the concerns regarding the effectiveness of basic skills courses at the community college level (Grubb \& Gabriner, 2012). While most research has examined the comparative merit and impact of specific placement practices, there is considerably less research on how placement in and of itself contributes to students' longer-term outcomes, such as degree completion, suggesting a need for additional research on this specific connection.

\section{Student Education Plans}

Much attention has been paid to the requirement that students develop a student education plan (SEP). In part, this is because unlike orientation and placement testing, which were identified in California's original program of matriculation services, the requirement that students develop an SEP is new. Many colleges have offered SEPs as a service through counseling, but participation in this service has varied.

According to Title $\mathrm{V}$, a student education plan:

"Take[s] into account a student's interests, skills, career and education goals, major, potential transfer institutions, and the steps the student needs to take on 
their educational path to complete their identified course of study. [...] The comprehensive plan includes, but is not limited to, addressing the education goal and course of study requirements, such as the requirements for the major, transfer, certificate, program, applicable course prerequisites or co-requisites" (5 $\mathrm{CCR} \S 55524)$.

Operationally, an SEP is a term-by-term plan of all the courses that a student needs to take to complete his or her educational goal, listed in the precise order in which the student should take them. SEPs are a way to provide students with a clear pathway of courses that allows them to meet degree requirements in the most efficient manner possible. The CCCCD colleges all provide SEPs in essentially the same manner. The majority of SEPs are developed by a counselor during an individual meeting with a student. During this meeting, the student and counselor discuss the student's short and long-term educational goals and develop a term-by-term plan that includes all required courses to meet the student's goal, including any prerequisite courses and basic skills courses, depending on the student's placement level and completed coursework. Students can use the resulting SEP document to plan their schedule each semester. More recently, the CCCCD colleges have implemented Student Planning, an online degree planning tool that students can use to independently develop their own SEP. Students are able to search for any degree or certificate program offered in the district, and Student Planning will show the student all of the courses that are required 
to complete that program. Because Student Planning integrates with CCCCD's student information system, Student Planning automatically matches students' completed coursework with program requirements and displays progress information about how close the student is to completing the program. Students use this information to populate a timeline with the courses they plan to take each semester and automatically receive a warning about any prerequisites or conflicts between their planned courses. This timeline is essentially the equivalent of an SEP, outlining the pathway to achieving a student's educational goal, but developed without the input of a counselor (Jeffrey Benford, personal communication, October 6, 2016).

While the body of literature specifically examining SEPs is limited, the concept of an SEP relates to a growing body of literature on structured degree pathways. The degree pathway concept has grown out of research examining the negative impact of choice on community college students' persistence and completion rates. Community colleges offer an array of choices to meet the needs of the varied population they serve: degrees and certificates, transfer-oriented courses and vocational courses in a vast array of subjects. Several researchers (Dadgar, Venezia, Nodine, \& Bracco, 2013; Jaggars \& Fletcher, 2014; Jenkins \& Cho, 2013; Scott-Clayton, 2011) have examined this abundance of choice in light of research in the areas of psychology and behavioral economics. 
Behavioral economists have found that the presence of too many choices negatively affects the decision-making process. When presented with too many choices, individuals become overwhelmed and are more likely to base their decisions on the context in which choices are presented (Tversky \& Simonson, 1993). Because community colleges offer so many course choices and provide unclear pathways to degrees and certificates, students typically do not plan their courses in the most efficient way. Inefficient course planning leads to taking courses that do not fulfill the degree requirements, which leads to excess units and delays student completion (Zeidenberg, 2012). Similar research has found that presence of a large number of choices, especially choices that are complex and require research, increases the likelihood that people will procrastinate in making a decision or select the default option (Beshears, Choi, Laibson, \& Madrian, 2008). A relevant example of this kind of complex decision-making scenario is the choice that an undeclared community college student must make between an array of majors and unclear general education plans. Researchers such as Scott-Clayton (2011) have found that without guidance in making this choice, such students either put off declaring a major and take classes aimlessly, or choose the default option of dropping out.

In light of this research, a number of institutions across the country have engaged in reform efforts to help students identify a major and streamline academic program requirements (Carey, 2008; Jenkins \& Cho, 2013; Johnstone, 2015). The goal 
of these reform efforts has been to connect students to degree programs with clearly structured pathways that provide an opportunity for some degree of exploration in a context that ensures that students fulfill degree requirements in an efficient manner. Such institutions have seen their student persistence and completion rates increase following implementation of these reforms.

Two of the colleges who have implemented such reforms are Miami Dade College and Georgia State University. Beginning in 2012, in response to low completion rates, Miami Dade College engaged in a comprehensive redesign of their curriculum and student services in order to foster better outcomes for students. Among the elements of the redesign were the establishment of a comprehensive intake process where students met with an advisor to develop an education plan, the development of structured programs that aligned with transfer and career requirements, and the requirement that students choose a broad "community of interest" matching their academic and career goals. The college found that students who developed a plan with an advisor had a retention rate that was 8 percent higher than students who did not meet with an advisor (Rodicio, Mayer, \& Jenkins, 2014). Similarly, starting in the late 1990s, Georgia State University began implementing a series of initiatives to address its low completion rates. Georgia State's initiatives were multi-faceted. One initiative involved assigning incoming freshmen to a learning community based on their selected "metamajor", a concept similar to the "communities of interest" at Miami Dade. Another 
included identifying bottlenecks that limited student persistence in academic programs and adjusting the prerequisites and GPA requirements of the programs to reduce these bottlenecks while maintaining program integrity. They also implemented a new advising model that drew upon a new database of student success data to help provide advisors with more useful information about students' barriers to success. The result of these initiatives has been a dramatic increase in the university's six-year completion rates, which have increased from 32 percent in 2003 to 54 percent in 2014 (Kurzweil \& $\mathrm{Wu}, 2015)$. These findings are even more noteworthy given that during the same period the percentage of students receiving Pell Grants has nearly doubled and the percentage of non-white students has increased from 40 to 60 percent.

SEPs are a personalized version of the degree pathways that the aforementioned studies have correlated with higher rates of student persistence and completion. Since this is a relatively new service, the body of literature that specifically examines the impact of SEPs on student persistence and completion is small. Researchers have found that students who receive an SEP complete more units and transfer requirements (Myers, 2012), have higher persistence rates (Rodicio et al., 2014), and are more likely to complete their degree (Gantt, 2010; Rodwell, 2014). However, related research indicates a strong correlation between receipt of an SEP and other factors such as ethnicity (Myers, 2012) or participation in a student success class (Goomas, 2012), factors that are independently correlated with student success. As a result, these studies 
call into question whether one can attribute such positive outcomes solely to the receipt of an SEP.

\section{Counseling}

Like orientation and placement testing, counseling is not a new service in California community colleges. Unlike orientation, placement testing, and education planning services, the Student Success Act specifies a more limited population of students who must visit a counselor, specifically students with poor academic standing, undeclared students, basic skills students, (Seymour-Campbell Student Success Act, 2012, sec. 55523), and first time students (sec. 51018).

Similar to SEP services, the provision of counseling services does not vary much between the CCCCD colleges. While the number and assignment of counselors employed at each college is different, each college has a team of counselors who provide academic, career, and personal counseling to enrolled students. While some counselors specialize in serving specific populations, such as student athletes or students with disabilities, the majority of counselors are generalists who are available to serve all students. There is no requirement for students to meet with a counselor, and there is also no limit to the number of times a student can visit a counselor during their academic career. However, counselor availability is limited, and appointments are available on a first-come, first-served basis. In-person counseling appointments are typically 30 minutes, though the colleges also offer drop-in counseling for brief 
questions and issues, and online counseling for students who cannot visit the counseling department within the available hours.

There is a growing body of literature on the impact of counseling and academic advising on student success, which explains its inclusion among the required SSSP services. Bahr (2008) conducted a study of the impact of counseling and advising services for nearly 200,000 students in California community colleges. He found that academic advising had a significant and positive impact on students' likelihood of successfully completing a remedial mathematics sequence or transferring to a four-year university. Additional studies have built upon and replicated these findings for specific groups of students, indicating that counseling had a positive impact on persistence for students in science and math programs (Packard \& Jeffers, 2013) and financial aid applicants (McKinney \& Novak, 2013). It is clear that counseling and academic advising play an important role in the success of community college students.

Within this body of literature, there are several types of counseling that have been studied for their comparative impact on student success. This partly reflects recent trends toward identifying innovative new ways to engage and support students, especially those who may not be motivated to independently seek out counseling services on their campus. One area of research has examined the approach of "intrusive advising" where counselors or academic advisors play a more active role in reaching out to and working with students. This can include having instructors trained to provide 
advising to their students, either within or outside of the classroom (Ryan, 2013). Ryan's study found that this model of intrusive advising resulted in students with higher retention rates and grade point averages compared to students in a matched course section that did not receive intrusive advising.

Other forms of intrusive advising services are characteristic of a variety of special programs that exist at community colleges in order to provide additional support to at-risk students. Fowler and Boylan (2010) examined the impact of a special program for underprepared college students called "Pathways to Success," which provides a number of intensive support services for students. Program participants must enroll fulltime in a prescribed course schedule, attend an orientation session, meet with a counselor three times per semester, and participate in tutoring if their grades fell below a C. This model of intrusive advising is different from the Ryan (2013) study in that students' instructors were not directly providing advising; however, the "Pathways to Success" instructors did communicate frequently with the students' counselors if students' achievement began to decline or if they exhibited behaviors such as excessive absence or failure to turn in assignments (Fowler \& Boylan, 2010, p. 6). Students in the "Pathways to Success" program had higher grade point averages, were more likely to be in good academic standing, were more likely to complete their developmental classes, and had higher persistence rates than matched peers. California community colleges have a number of specialized programs that offer similar services to those described by 
Fowler and Boylan, such as Extended Opportunity Programs and Services (EOPS), Math Science Engineering Achievement (MESA), Puente, and Umoja, which each target specific categories of at-risk students.

\section{Mandated Services and Underrepresented Students}

Because the secondary research questions for this study concern the effect of participation in student support services on the outcomes of students from identified underrepresented groups, it is important to examine the degree to which the literature has identified any significant differences in the impact of such services for these populations.

A few studies specifically concern participation in orientation services for students from underrepresented groups. Derby (2007) studied a cohort of students who participated in a semester-long orientation course and compared their graduation rates to that of their peers who did not take the course. Using regression analysis, Derby found that for the overall sample of students who took the orientation course, students who took the course were 72 times more likely to graduate than their peers who had not taken the course - a significantly positive, albeit curiously large, effect. However, when the author used a different regression model that incorporated student demographics, including ethnicity, there was no statistically significant effect for the African-American and Hispanic students who had participated in the course; their likelihood of graduating was comparable to that of their peers who had not taken the orientation course. This is 
particularly noteworthy, given the literature's mixed conclusions regarding the effectiveness of orientation in producing positive outcomes for students. This suggests that even when evidence suggests that an orientation course has an overwhelmingly positive effect on students at large, African-American and Hispanic students may not experience the same benefit.

Counseling and Advising is another area where some research has looked specifically at the differential impact of services on students from underrepresented backgrounds. Bahr (2004) studied community college students in a remedial math program, a subset of whom received supplemental services, including academic advising, to help them successfully complete the course. An interesting set of findings emerged related to students in the math program who had and had not participated in advising services. While white and Asian students who received advising were more likely to successfully complete the course than their peers who did not receive advising services, Hispanic students experienced no significant effect from advising services. Of even greater concern, the African-American students in the program who also received academic advising services were actually less likely to complete their remedial math class than the African-American students in the program who did not receive advising services.

Bahr went on to conduct a 2007 study attempting to replicate these findings. Hypothesizing that advising services may be a subtle form of institutional racism 
designed to "cool out" community college students from underrepresented backgrounds, he examined the effect of advising services on students in two cohorts: unprepared students (students who had tested into remedial math) and transfer-directed students (students who had indicated an educational goal of transferring to a 4-year university). The findings were mixed. Students in the unprepared cohort, regardless of ethnicity group, all experienced a statistically significant, positive effect on successful course completion from participating in academic advising. Furthermore, for students who were both unprepared and transfer-directed, there was evidence that in terms of successful transfer-outcomes, the unprepared students benefitted slightly more from academic advising than prepared students in the transfer-directed cohort. However, for transfer-directed students, while students across all ethnic groups experienced a significant, positive effect from advising on their likelihood of transfer, AfricanAmerican students benefitted from advising services to a lesser degree than did their white peers. This is noteworthy, because it suggests that students' ethnicity may exercise a subtle effect on how they experience academic advising.

To take a closer look at the educational experiences of Hispanic students, Sanchez (2012) conducted a mixed methods case study on the transfer aspirations and educational barriers of Hispanic students at a California community college. One of the unexpected findings concerned students' participation in the college's matriculation services: orientation, placement testing, and an initial advising appointment with a 
counselor, which included a degree-planning component. A subset of students in the study were part of a program that required students to participate in all of these services, while others were either not part of the program or had been waived from participating in the services. Sanchez found that students who participated in the matriculation services were more likely to have persisted beyond the first semester and had a more realistic sense of the timeline and barriers to transferring, relative to their preparation level. Similarly, students who had not completed the matriculation services, regardless of their status in the program, reported vague or unrealistic timelines for transferring and were more likely to have taken a semester off or have dropped out of school entirely. These findings are noteworthy, not only because they concern the same SSSP services that are the focus of this study, but because they address some of the noncognitive factors that may be related to participation in SSSP services. Sanchez's other findings included the observation that Hispanic students have numerous non-academic barriers to persisting and transferring. Some of these barriers are academically related, such as a higher likelihood of testing into basic skills classes, particularly in English or ESL. However, other barriers are non-academic, which may partly be reflected in the finding regarding participation in matriculation services. Because Sanchez's study was limited to Hispanic community college students, it is unclear whether these characteristics might be unique to this population or generalizable to students from disadvantaged groups in general. Sanchez suggested that some of these barriers might 
be mitigated by continued participation in counseling and advising services, which reinforced conclusions from Ornelas and Solarzano (2004) that have been extended to other disadvantaged groups.

\section{Other Factors Related to Student Success}

While these core services of orientation, placement testing, and student education plans are the emphasis of the Student Success Act, researchers have identified a number of other factors that have a positive impact on the success of community college students. Some of these factors were discussed in the recommendations of the Student Success Task Force, such as full-time enrollment or declaring a major. Given that the purpose of this study is to evaluate the comparative impact of the services mandated by the Student Success Act, it is important to consider other factors that may provide an alternative explanation for students' success and completion.

Full-time enrollment is one such factor of interest. A full-time student is one who enrolls in at least 12 semester units. One of the secondary recommendations of the Student Success Task Force was to provide students with information regarding the benefits of enrolling in college full-time (California Community Colleges, Student Success Task Force, 2011). The Center for Community College Student Engagement (CCCSE) has conducted national surveys of community college students for over a decade and have tracked student participation in activities and high-impact practices that they term "engagement," such as active class participation, partaking in tutoring or 
other academic work outside of class, and communicating with faculty. Their research indicates that behaviors under the umbrella of engagement are highly correlated with successful outcomes for students. They have consistently identified that full-time students report higher levels of engagement than do part-time students (Center for Community College Student Engagement, 2015). Several other researchers have identified a positive relationship between full-time enrollment and specific student success outcomes. O'Toole, Stratton, and Wetzel (2003) found that full-time students had significantly higher five-year graduation rates and higher persistence rates than part-time students. Ifill et al. (2016) had similar findings in their recent analysis of firsttime students three years after initial enrollment. While full-time enrollment is a luxury that not all community college students may be able to afford, the literature does support the notion that students who enroll in college full-time tend to fare better than students who enroll part-time.

Similar to full-time enrollment, persistence is a characteristic of student enrollment that is frequently correlated with positive student outcomes. To understand persistence as a factor influencing completion, and not an outcome in and of itself, it is important to note the distinction between stopping out and dropping out. Stopping out refers to students who take an enrollment gap for one or more full semesters before reenrolling, whereas dropping out refers to students who cease enrollment and never return. In this context, persistence indicates students' continuous enrollment without 
stopping out. Enrollment gaps have been observed by community college researchers dating back to Tinto (1987), and are common among community college students, especially among those who are balancing work and family responsibilities, or those

who are still clarifying their educational goals. Many students who stop out do return to continue or complete an educational goal; however, research has shown that even students who re-enroll have lower rates of completion than students who enroll continuously (Adelman, 2005). Data from the National Center for Education Statistics indicates that, over a 6 year period, students who began at a community college and maintained continuous enrollment were more likely to have completed a degree or certificate than those who had stopped out at least once during the 6 year period (Skomsvold, Radford, \& Berkner, 2011). Similar to full-time enrollment, continuous enrollment is a factor that students are often unable to choose, but is nonetheless correlated with positive student outcomes.

\section{Conclusions}

This review provides some evidence that the services mandated by the Student Success Act are not without merit. For each of the core services, there are studies that identify a positive relationship between the service and student success factors such as persistence, grade point average, and degree completion. However, this review highlights a number of questions and concerns with the services that merit additional research. First, some services, like orientation, are not implemented using the same 
framework as most of the corresponding literature, so the specific impact of this type of orientation is not well understood. Additionally, the literature regarding placement practices is mixed, calling into question the methods colleges use to place students into college-level coursework. Further, some services, like student education plans, are too new of a concept to have a significant body of operational literature regarding their effectiveness. Finally, most of the extant research examines only one services in isolation, without consideration for the relative impact of any one service. It is also important to consider other factors, such as full-time enrollment, for which evidence exists to suggest that they also impact students' success and completion. For these reasons, it is clear that the extant research provides insufficient evidence to address the research questions regarding the relationship between the SSSP mandated services and student completion. 


\section{Chapter Three: Methodology}

This chapter provides a detailed account of the quantitative research methodology utilized in this study. The chapter begins with an overview of the research design and a description of how the methodology aligns with the research questions. It then describes the role of the researcher and the context and population of the case study. The chapter goes on to describe the data collection process, including an overview of all variables utilized in the study. Finally, the chapter describes the data analysis procedures, including the processes of cleaning data, deriving select variables, and conducting the quantitative analysis.

\section{Introduction}

The purpose of this study is to explore the relationship between the services mandated by the Student Success Act and students' completion of an educational goal for students in the Contra Costa Community College District (CCCCD). Secondary analyses explore the nature of this relationship as well as variations in the relationship for students belonging to various groups that the district identifies as underrepresented.

While the current relevance of this study is the mandated services of the Student Success Act, these mandates have only just gone into effect for the Fall 2014 semester. This post-hoc analysis of a cohort of students who first enrolled in the CCCCD several years ago can serve as a proxy for measuring the future impact of the mandated services. Students in that cohort have received the mandated services at different 
frequencies. These differing frequencies create a greater variety of sample groups and allow the mandated services to be studied independently as well as comparatively. Furthermore, a period of six years from students' initial term of enrollment was selected because the California Community College system has an established practice of using a period of six years when calculating graduation rates for its college (California Community Colleges Chancellor's Office, n.d.).

\section{Research Design}

This study used a logistic regression model to determine which combination of support service utilization is most predictive of successful completion of an educational goal: either a degree, certificate, or attainment of transfer-prepared status (completion of 60 degree-applicable units with a GPA of 2.0 or higher). Binary logistic regression was selected as the preferred quantitative methodology because the outcome variable was a dichotomous (completed educational goal $=1$, did not complete $=0$ ).

Because one possible outcome of this study was that none of the mandated services is most predictive of students' success, a number of other variables were collected. This way, the mandated services could be compared not just to each other, but also to other factors, to determine the mandated services' overall impact on successful student outcomes, and determine whether other factors are more strongly correlated with students' success than any of the mandated services.

\section{Role of the Researcher}


The primary researcher had no direct interaction with the study participants. The researcher had no role in collecting the data, only in developing a list of variables of interest that should be present in the dataset. The CCCCD Office of Institutional Research compiled the dataset and supplied it to the researcher. Subsequently, the researcher recoded the raw data, conducted the quantitative analysis, and interpreted the findings.

The researcher has specific expertise in the subject of this analysis, the Student Success Act. The researcher is employed as an Administrative Systems Analyst at a community college that is in the midst of implementing the mandates of the student success act. As an analyst assigned to supporting the activities of the Student Success Act, the researcher oversees the technical implementation and reporting of the services analyzed in this study.

\section{Population, Sample, and Context}

The study's population is students enrolled in the Contra Costa Community College District (CCCCD). The CCCCD has been serving the community of Contra Costa County for over 65 years. It has grown to be one of the largest community college districts in California with three colleges that serve a diverse community of over one million residents including a population of over 55,000 students annually. The three colleges offer a wide array of curriculum leading to an associate's degree, transfer to four-year universities, and specialized vocational training. 
The sample obtained for this study was the cohort of students who enrolled in the CCCCD for the first time in the 2008-2009 academic year. The original dataset provided by the office of institutional research contained 9,682 student cases, grouped into demographic information (one record per student) and progress information (one record per student per term). The target population of this study is first-time community college students enrolled in the CCCCD. A number of cases were excluded from the original sample because they did not meet the criteria of "students primarily enrolled at a community college." Students who are not primarily enrolled at a community college are excluded from the mandates of the Student Success Act, since they are not considered matriculated students; as such, these students are outside the scope of this study. There were three categories of students who were not considered "primarily enrolled at a community college": students who reported on their college application that they had previously earned an AA or higher degree, students who indicated that they were 4-year college students taking courses to meet 4-year college requirements, and K-12 students concurrently enrolled in college classes. The final sample included 7,729 student records.

The CCCCD enrolls a diverse population of students, and this sample reflects the district's diversity. Some of the ethnic groups present in the original dataset were consolidated, both due to small numbers of cases and to follow the CCCCD conventions for reporting ethnic groups. Cases with an ethnicity of Filipino or Pacific Islander were 
combined with Asian, and American Indian were combined with Unreported and relabeled "Other Ethnicity." For the purposes of this study, student financial aid status was used as a proxy for socioeconomic status, where students who received any form of need-based financial aid while enrolled in the district are considered low-socioeconomic status and students who never received any form of financial aid are considered highsocioeconomic status.

Table 3.1

Ethnicity of Sample, by Campus and Overall

\begin{tabular}{|c|c|c|c|c|c|c|c|c|}
\hline \multirow[b]{2}{*}{ Ethnicity } & \multicolumn{2}{|c|}{$\mathrm{CCC}$} & \multicolumn{2}{|c|}{ DVC } & \multicolumn{2}{|c|}{ LMC } & \multicolumn{2}{|c|}{ Overall } \\
\hline & $\mathrm{N}$ & $\%$ & $\mathrm{~N}$ & $\%$ & $\mathrm{~N}$ & $\%$ & $\mathrm{~N}$ & $\%$ \\
\hline White & 193 & 14.0 & 1,875 & 44.6 & 719 & 33.5 & 2,787 & 36.1 \\
\hline Black & 362 & 26.2 & 286 & 6.8 & 390 & 18.2 & 1,038 & 13.4 \\
\hline Hispanic & 407 & 29.5 & 493 & 11.7 & 548 & 25.6 & 1,448 & 18.7 \\
\hline Asian & 279 & 20.2 & 694 & 16.5 & 218 & 10.2 & 1,191 & 15.4 \\
\hline Multi-Race & 52 & 3.8 & 198 & 4.7 & 148 & 6.9 & 398 & 5.1 \\
\hline Other & 89 & 6.4 & 657 & 15.6 & 121 & 5.6 & 867 & 11.2 \\
\hline Total & 1,382 & 100.0 & 4,203 & 100.0 & 2,144 & 100.0 & 7,729 & 100.0 \\
\hline
\end{tabular}

Table 3.2

Financial Aid Status of Sample, by Campus and Overall

\begin{tabular}{|c|c|c|c|c|c|c|c|c|}
\hline \multirow[b]{2}{*}{ Financial Aid Status } & \multicolumn{2}{|c|}{$\underline{\mathrm{CCC}}$} & \multicolumn{2}{|c|}{$\underline{\mathrm{DVC}}$} & \multicolumn{2}{|c|}{$\underline{\mathrm{LMC}}$} & \multicolumn{2}{|c|}{ Overall } \\
\hline & $\mathrm{N}$ & $\%$ & $\mathrm{~N}$ & $\%$ & $\mathrm{~N}$ & $\%$ & $\mathrm{~N}$ & $\%$ \\
\hline Received Aid & 547 & 39.6 & 814 & 19.4 & 824 & 38.4 & 2,185 & 28.3 \\
\hline Did not Receive Aid & 835 & 60.4 & 3,389 & 80.6 & 1,320 & 61.6 & 5,544 & 71.7 \\
\hline Total & 1,382 & 100.0 & 4,203 & 100.0 & 2,144 & 100.0 & 7,729 & 100.0 \\
\hline
\end{tabular}

Each of the three colleges has a different demographic profile, as summarized in Tables 1 and 2. CCC has the largest percentage of students from underrepresented minorities: 26 percent of students are African-American and almost 30 percent are 
Hispanic. It also has the largest percentage of Asian students (20 percent) and the largest percentage of students receiving financial aid (40 percent). DVC has the largest population of white students in the district (45 percent), but also has significant percentages of Asian and Hispanic students (17 and 12 percent, respectively). It also has the largest percent of students who describe themselves as Other/Unspecified (16 percent). DVC has the smallest percentage of students who receive financial aid (19 percent). While white students make up the largest group at LMC (34 percent), LMC has the largest number of Hispanic students in the district, making up 26 percent of their local population, and the largest percentage of students reporting multiple ethnicities (7 percent). There are also significant percentages of African American and Asian students (18 and 10 percent, respectively). LMC also has the largest number of students receiving some form of financial aid, making up 38 percent of their population.

\section{Data Collection}

The data collected are archival data routinely collected by the CCCCD and stored in the district's student information system database. Data access was gained by requesting permission through the Office of Institutional Research. The Office of Institutional Research assembled the dataset according to the specifications of the researcher, with no personally identifiable information supplied. The dataset included records for all students who attended college in the CCCCD for the first time in the 2008-09 academic year. All data were stored electronically in Excel spreadsheets for 
cleaning and derivation of variables, then transferred to IBM SPSS Statistics Version 22 for analysis.

\section{Variables}

Fourteen different variables were collected for use in this regression model, in order to get a full picture of students' background, experience at the college, and educational outcomes.

One dependent variable was used throughout this study to measure students' successful completion of an educational goal. This variable was dichotomous to indicate completion of either an associate's degree, completion of a certificate, or attainment of "transfer prepared" status. Transfer-prepared status is defined as completion of 60 degree-applicable units with a GPA of at least 2.0 (California Community Colleges Chancellor's Office, n.d.)

Four independent variables relate to the Student Success Act's mandated support services. Three of the variables are categorical, indicating participation in the identified service. Orientation had three categories of service participation: attendance at an inperson orientation workshop, completion of online orientation, and a reference group of no orientation received. Student education plan (SEP) had three non-independent categories. Students could have received an SEP from a counselor, developed an SEP using the district's self-service online degree-planning tool, received both forms of an SEP, or received no SEP. For the sake of the regression analysis, this was recoded as 
two dichotomous variables: counselor SEP (with a reference group of no SEP from a counselor) and online SEP (with a reference group of no online SEP). Assessment was dichotomous to indicate completion of one or more placement subtests, with a reference group of no placement test taken. The number of contacts a student had with a counselor was also collected, which is ratio data. These are the variables of interest in this study's three research questions, which examine different aspects of the correlation between these services and students' success.

The researcher selected eight confounding variables to determine whether they affect the relationship between the independent variables of interest and the outcome variable. They may also provide an alternate hypothesis for students' completion of the outcome variable. Four confounding variables relate to other academic factors of interest. These include initial declared major, initial educational goal, full-time enrollment status (expressed as a ratio of terms enrolled full-time out of total terms enrolled), and number of terms persisted without stopping out. Because the first two of these had so many categorical options (over 300 academic programs and 15 educational goals), they were both recoded as dichotomous variables for the purpose of logistic regression analysis. Declared major was recoded as declared or undeclared, in part because over one-third of students declared a major of undecided at the time of application. Educational goal was recoded as completion-oriented (a goal of completing a degree, certificate, or transferring), not completion-oriented, and 
undecided/unspecified, which was the reference group. Similar to declared major, a majority of students did not select an educational goal, or selected a goal of undecided. Five confounding variables concern students' demographics, three of which were used to classify students as belonging to one of the underserved groups identified in the second and third research questions. These include ethnicity, gender, financial aid status, disability status, and age at initial enrollment. The categories for ethnicity are Hispanic, African-American, Asian (which included Filipino and Pacific Islander), Multi-Ethnic, Other/Unspecified (which included Native American), and the reference group of White. These ethnicity categories are consistent with the groupings used by the CCCCD Office of Institutional Research. Financial aid status was dichotomous to indicate whether or not students received any form of need-based financial aid (such as a Board of Governor's fee waiver or Pell grant). Disability status was dichotomous to indicate whether or not students had registered with their college's Disability Support Services office.

Additional variables were collected as part of the initial dataset and were either used solely for the derivation of other variables, or were excluded from analysis due to low response rates. The variables of completed units, grade point average, enrollment status, and cumulative completed degree-applicable units were all collected as part of the initial dataset and were utilized solely to derive variables of interest (ratio of terms enrolled full-time, and the dependent variable of "transfer prepared status"). The 
variables of English placement level and math placement level, which were coded as ordinal variables corresponding to either prepared for college level coursework, or one of many possible levels below college-level. These variables were considered as other academic variables of interest, given that the majority of community college students require some amount of basic skills remediation (California Community Colleges, Student Success Task Force, 2011; Grubb \& Gabriner, 2012). However, these two variables were excluded from the final analysis because they would have limited the analysis to the 32 percent of the sample who had participated in both placement tests.

\section{Data Analysis Procedures}

In preparation for statistical analysis, the researcher reviewed the records of students identified in the target population. 67 records were identified as duplicates due to students attending more than one college in the district. After verifying that the contents of the matching records were identical, the researcher removed the duplicate records and updated the preserved cases to reflect the students' attendance at both colleges.

Next, the researcher recoded and organized the sample's variables, grouping them as independent variables, confounding variables, and dependent variables. Categorical variables with more than two categories were recoded into k-1 dichotomous dummy variables, where $\mathrm{k}$ is the number of categories, in preparation for logistic regression analysis. Some variables had to be derived or consolidated from several data 
points into a single variable, because the data were provided as progress variables (one record per student per term). Such variables include number of terms enrolled, cumulative units completed (total and degree-applicable), cumulative grade point average, percent of terms enrolled full time, and attainment of transfer-prepared status (completion of 60 degree-applicable units with a GPA of at least 2.0).

The dataset was loaded into SPSS for quantitative analysis. Descriptive statistics were calculated to organize and summarize the dataset. 385 cases were screened out for having missing information for one or more of the demographic variables. Because the dependent variable is dichotomous, a binary logistic regression model was used to calculate the correlations between the mandated services of the Student Success Act and the outcome of completion of an educational goal, and compare the mandated services and other variables in terms of their relative weight in predicting a student's likelihood of completing a degree. The result is a conceptual model of the relationship between each variable and completion outcomes.

To address the secondary research questions, logistic regression analysis was conducted using the various subgroups of interest, including specific ethnic groups, financial aid recipients, and students with disabilities. The goal of the follow-up analyses was to identify any differences between the subgroups and their respective comparison groups in terms of the relationship between service utilization and degree 
completion, including which services are most predictive of successful outcomes for each group.

\section{Reliability and Validity}

Several measures were taken to maintain the reliability and validity of this study. The use of raw data from a single source increases the reliability and internal consistency of the data (Cone \& Foster, 2006). The size of the sample is large enough to improve the statistical power of the test and reduce the likelihood of type II errors (whereby one accepts the null hypothesis when it is actually false). Subjects with incomplete data were identified and removed, if necessary, without significantly impacting the sample size and characteristics. Selection bias is reduced by studying an entire population (all students who enrolled in the CCCCD during the selected year), rather than selecting a subset of cases. One possible threat to internal validity is that extraneous variables not accounted for in this study could have an impact on students' completion. This is a limitation of using existing data from the institution's student information system, because available information was limited to data collected on the college's application and information collected for the purpose of state mandated reporting; data involving student motivation or other factors are unavailable. Collecting data on a wide range of variables mitigates this threat to some extent by accounting for as many causal factors as possible. 
Concerns regarding reliability and external validity are minimal because the primary audience of this study is the Contra Costa Community College District. As such, claims of the generalizability of the results of this study will be limited to similar students within the CCCCD. 


\section{Chapter Four: Report of Findings}

This study analyzed the completion of an educational goal for students who enrolled in the Contra Costa Community College District (CCCCD) for the first time in the 2008-09 academic year. The goal of this analysis is to explore the extent to which participation in services mandated by the Student Success Act predicts completion of an educational goal for CCCCD students. Secondary research questions examine the nature of this relationship for students from various underrepresented groups.

\section{Descriptive Statistics}

Of the 7,729 students included in the analysis, only $1,826(23.6 \%)$ persisted to complete an educational goal. Of the students completing an educational goal, 410 (22.5\%) completed an Associate's Degree, 366 (20.0\%) completed a certificate, and 1,623 (88.9\%) attained transfer-prepared status (completion of 60 degree-applicable units with a grade point average of 2.0$) .502$ students ( $27 \%$ of completers) completed more than one educational goal.

As predicted, students completed the mandated support services at different rates. 1,227 students (15.9\%) completed an orientation. Of these students, $93.4 \%$ completed an in-person orientation workshop as opposed to an online orientation. 1,718 students (22.2\%) received a student education plan (SEP). $94.1 \%$ of those who received an SEP received a plan developed by a counselor, versus $12.2 \%$ who used the district's online, self-service degree-planning tool; 109 students received both kinds of SEP. 
Table 4.1

Percentage and Number of Students by Categorical Variable

\begin{tabular}{|c|c|c|c|}
\hline Variable & Value & $\mathbf{n}$ & $\%$ \\
\hline \multirow[t]{5}{*}{ Completed } & Completed any goal (AA, certificate, or transfer) & 1,826 & 23.6 \\
\hline & Completed Associate's degree (AA) & 410 & \\
\hline & Completed certificate & 366 & \\
\hline & Attained transfer-prepared status & 1,623 & \\
\hline & Did not complete (reference) & 5,903 & 76.4 \\
\hline \multirow[t]{2}{*}{ Counselor SEP } & Received SEP developed by a counselor & 1,617 & 20.9 \\
\hline & No SEP from a counselor (reference) & 6,112 & 79.1 \\
\hline \multirow[t]{2}{*}{ Online SEP } & Received SEP from the online, self-service tool & 210 & 2.7 \\
\hline & No online SEP (reference) & 7,519 & 97.3 \\
\hline \multirow[t]{3}{*}{ Orientation } & Orientation Workshop & 1,146 & 14.8 \\
\hline & Orientation Online & 81 & 1.0 \\
\hline & No orientation (reference) & 6,502 & 84.1 \\
\hline \multirow[t]{2}{*}{ Assessment } & 1 or more placement subtests taken & 4,698 & 60.8 \\
\hline & No placement test (reference) & 3,031 & 39.2 \\
\hline \multirow[t]{3}{*}{ Educational Goal } & Completion-oriented goal & 2,078 & 26.9 \\
\hline & Non-completion oriented goal & 1,079 & 14.0 \\
\hline & Unknown/unspecified goal (reference) & 4,572 & 59.2 \\
\hline \multirow[t]{2}{*}{ Declared Major } & Declared major at initial enrollment & 5,114 & 66.2 \\
\hline & Undeclared at initial enrollment (reference) & 2,615 & 33.8 \\
\hline \multirow[t]{2}{*}{ Financial Aid } & Received any form of need-based aid & 2,185 & 28.3 \\
\hline & No need-based aid received (reference) & 5,544 & 71.7 \\
\hline \multirow[t]{2}{*}{ DSS } & Registered with disability services & 311 & 4.0 \\
\hline & Not registered with disability services (reference) & 7,418 & 96.0 \\
\hline \multirow[t]{6}{*}{ Ethnicity } & Black & 1,038 & 13.4 \\
\hline & Hispanic & 1,448 & 18.7 \\
\hline & Asian (includes Filipino and Pacific Islander) & 1,191 & 15.4 \\
\hline & Multi-Ethnic & 398 & 5.1 \\
\hline & Other Ethnic & 867 & 11.2 \\
\hline & White (reference) & 2,787 & 36.1 \\
\hline \multirow[t]{2}{*}{ Gender } & Female & 4,058 & 52.5 \\
\hline & Male (reference) & 3,671 & 47.5 \\
\hline \multirow[t]{3}{*}{ Primary Campus } & Contra Costa College & 1,382 & 17.9 \\
\hline & Diablo Valley College & 4,203 & 54.4 \\
\hline & Los Medanos College & 2,144 & 27.7 \\
\hline
\end{tabular}

$\mathrm{n}=7,729$ 
4,698 students (60.8\%) took at least one subtest of the placement test. 3,227 students (41.8\%) had at least one appointment with a counselor. Students who saw a counselor ranged from having 1 to 13 advising contacts, with an average of .94 advising contacts per student.

Table 4.2 Means and Standard Deviations on Integer and Ratio Variables

\begin{tabular}{|l|l|r|r|r|r|}
\hline Variable & Description & Min. & Max. & Mean & $\begin{array}{r}\text { Standard } \\
\text { Deviation }\end{array}$ \\
\hline Counseling & $\begin{array}{l}\text { Number of contacts with a } \\
\text { lounselor/advisor }\end{array}$ & 0 & 13 & .94 & 1.532 \\
\hline $\begin{array}{l}\text { Full Time } \\
\text { Ratio }\end{array}$ & $\begin{array}{l}\text { Ratio of terms enrolled full } \\
\text { time out of total terms enrolled }\end{array}$ & 0.00 & 1.00 & .2920 & .33540 \\
\hline $\begin{array}{l}\text { English } \\
\text { Level } \\
(n=4,578)\end{array}$ & $\begin{array}{l}\text { Number of levels below } \\
\text { transferable English, based on } \\
\text { placement test }\end{array}$ & 0 & 2 & 1.04 & .750 \\
\hline $\begin{array}{l}\text { Math Level } \\
(n=2,570)\end{array}$ & $\begin{array}{l}\text { Number of levels below } \\
\text { transferable math, based on } \\
\text { placement test }\end{array}$ & 0 & 3 & 2.28 & .787 \\
\hline Terms & $\begin{array}{l}\text { Number of terms enrolled in the } \\
\text { district }\end{array}$ & 1 & 19 & 4.6 & 3.670 \\
\hline $\begin{array}{l}\text { Terms } \\
\text { Persisted }\end{array}$ & $\begin{array}{l}\text { Number of continuous terms } \\
\text { enrolled in the district without } \\
\text { stopping out (excluding } \\
\text { summer })\end{array}$ & 1 & 13 & 3.23 & 2.686 \\
\hline $\begin{array}{l}\text { Terms to } \\
\text { Completion } \\
(n=1,826)\end{array}$ & $\begin{array}{l}\text { Number of terms enrolled } \\
\text { before completing an } \\
\text { educational goal }\end{array}$ & 1 & 19 & 7.16 & 2.663 \\
\hline Units & Total units completed & 0 & 169.5 & 29.85 & 32.247 \\
\hline Age & Age at the end of the first term & 17 & 76 & 24.92 & 10.904 \\
\hline
\end{tabular}

$n=7,729$, except as otherwise indicated

\section{Logistic Regression Analysis}

A logistic regression was conducted to analyze the overall population. This model examined the effect of SSSP mandated services, other academic factors, and 
demographic variables on completion of an educational goal. The model was statistically significant, $\chi^{2}(18, N=7,729)=4049.584, p<.001$. The model explained between 41 percent (Cox and Snell $R^{2}$ ) and 61 percent $\left(\right.$ Nagelkerke $\mathrm{R}^{2}$ ) of the variance in completion of an educational goal and correctly classified 88 percent of cases. Additionally, the Hosmer and Lemeshow test is an indicator of goodness of fit, or how well the model fits the data. For the selected model, the Hosmer and Lemeshow statistic was $p=.143$. Because this is not statistically significant $(p<.05)$, this means that the model was a good fit for the data.

The second and third research questions were limited to students belonging to various underrepresented groups. To address these research questions, the same logistic regression model was used. The only difference is that because membership in one of the identified underrepresented groups was identified using the demographic variables (ethnicity, financial aid status, disability status), these models have a shorter list of demographic variables, because the demographic variables that indicate membership in one of the identified subgroups were obviously excluded from the corresponding model.

\section{Research Question 1}

The logistic regression model for the overall sample was constructed to answer the first research question: Which of the support services mandated by the Student Success Act are most predictive of successful educational outcomes for community college students? According to this model, the mandated services most correlated with 
Table 4.3

Logistic Regression Analysis Predicting Completion of Educational Goal for Overall Sample $(N=7,729)$

\begin{tabular}{l|crr}
\hline \multirow{2}{*}{ Predictor } & \multirow{2}{*}{ OR } & \multicolumn{2}{c}{$95 \%$ CI } \\
\cline { 2 - 4 } SEP (Counselor) & $1.649^{* * *}$ & 1.374 & UL \\
SEP (Online) & $1.615^{*}$ & 1.056 & 2.470 \\
Orientation Workshop & $.749^{* *}$ & .612 & .916 \\
Online Orientation & .628 & .291 & 1.358 \\
Assessment & $1.366^{* *}$ & 1.115 & 1.674 \\
Counseling & $1.587^{* * *}$ & 1.504 & 1.676 \\
Declared Goal (Completion) & 1.077 & .906 & 1.280 \\
Declared Goal (Non-Completion) & .809 & .603 & 1.087 \\
Declared Major & $1.435^{* * *}$ & 1.201 & 1.713 \\
Full-Time & $7.711^{* * *}$ & 5.973 & 9.955 \\
Persistence & $1.658^{* * *}$ & 1.604 & 1.714 \\
Financial Aid & $.776^{* *}$ & .647 & .932 \\
Disabled & $.475^{* * *}$ & .318 & .709 \\
Hispanic & $.784^{*}$ & .622 & .989 \\
African-American & $.380^{* * *}$ & .281 & .513 \\
Asian & $1.291^{*}$ & 1.035 & 1.611 \\
Multi-Ethnic & $.681^{*}$ & .472 & .982 \\
Other/Unspecified Ethnicity & $1.469^{* *}$ & 1.151 & 1.876 \\
\hline
\end{tabular}

$* \mathrm{p}<.05, * * \mathrm{p}<.01, * * * \mathrm{p}<.001$

Likelihood Ratio (Chi Square) $\quad .000$

Cox \& Snell $\mathrm{R}^{2}$

.408

Nagelkerke $\mathrm{R}^{2}$

.613

Hosmer and Lemeshow Test

.143

Percent Correct

.881

Note: $O R=$ odds ratio; $\mathrm{CI}=$ confidence interval; $\mathrm{LL}=$ lower limit; $\mathrm{UL}=$ upper limit

community college students' success (completion of a degree or certificate or

attainment of "transfer-prepared status") are Counseling, an SEP (Student Education

Plan) from a counselor, an SEP from the online tool, and Assessment. The likelihood of

completing was 1.59 times higher for students who had one visit with a counselor, 
versus students who did not see a counselor. Furthermore, 23 percent of students saw a counselor more than once, and because advising is an integer variable, these students are even more likely to complete, with their likelihood of completion increasing proportionately for each additional advising contact. Compared to students who did not receive an SEP, the likelihood of completing was 1.65 times higher for students who received an SEP from a counselor and 1.62 times higher for students who created an SEP through the online degree-planning tool. Students who participated in assessment were 1.37 times more likely to complete than students who did not take the placement test.

While the first research question specifically concerns the SSSP services that positively predict completion, it is worth highlighting the one SSSP service that does not support the hypothesis: orientation. Not only is orientation left out among the variables that positively predict completion, but attending an orientation workshop actually has a significantly negative effect. Students who attended an orientation workshop were approximately 25 percent less likely to complete an educational goal (0.75 times as likely) versus students who did not attend orientation. This finding is unexpected and will be discussed further in chapter 5 .

Most academic factors correlate positively with students' success, namely full time enrollment status (percentage of terms enrolled full time out of total terms enrolled), persistence, and declaration of a major at the time of application. Persistence 
and declaration of a major had similar odds ratios as the mandated services, increasing students' likelihood of completing by 1.66 and 1.44 times, respectively. Full-time status had the most significant impact on completion; students who enrolled full-time every term were 7.71 times more likely to complete than students who never enrolled fulltime.

While not germane to this research question, it is noteworthy to look at the effects for the various demographic variables in the overall sample. All of these variables were significant in the model, and aside from the ethnic groups of Asian and Other/Unspecified, each demographic variable was a significantly negative predictor of completion. This means that students in each of these groups are significantly less likely to complete their educational goals, compared to students from the white, high-SES, non-disabled reference group. This finding has serious social justice implications and underscores the importance of conducting secondary analyses on students from each of these groups.

\section{Research Question 2}

Additional logistic regression analysis was conducted to answer the following research question: "How do the relationships between students' utilization of support services and their educational outcomes differ among students from identified underrepresented backgrounds (Hispanic, African-American, low socioeconomic status, disabled)?" The models for each of the four underrepresented groups (Hispanic, 
African-American, low socioeconomic status, and disabled) and the corresponding reference groups were all constructed using the same logistic regression model as the overall population. For the purposes of this research question, the outcome variable of "successful educational outcomes" is defined as completion of an educational goal, either a certificate, degree, or attainment of transfer-prepared status.

Many of the services and factors that were significant predictors of completion for Hispanic and African-American students were also significant predictors of completion for white students. These factors include receiving an SEP from a counselor (126\% more likely for Hispanic students and 88\% more likely for African-American students compared to white students), visiting a counselor (37\% more likely for Hispanic students and 51\% more likely for African-American students compared to white students), full-time enrollment status, and persistence, all of which positively predict a student's completion of an educational goal.

There are a few notable differences between Hispanic and African-American students when compared to the white students. While assessment and declaration of a major at initial enrollment were both significant predictors of completion for the white students, neither of these variables were significant for Hispanic and African-American students. Follow-up analysis of students who took the placement test, disaggregated by ethnicity, indicated that both Hispanic and African-American students were more significantly more likely than white students to test into the lowest levels of basic skills 
English. Compared to only $18 \%$ of white students, $42 \%$ of both Hispanic students and African-American students tested 2 or more levels below transfer-level English. Furthermore, $57 \%$ of African-American students tested 3 or more levels below transferlevel math (compared to $44 \%$ for white students). The finding that these students perform worse on the placement test than their white peers provides a possible theory for why assessment testing did not significantly contribute to these students' likelihood of completing, since they are less likely to receive the positive benefit of placing into transfer-level courses.

There are two additional noteworthy findings for Hispanic students. First, unlike their white peers, Hispanic students experienced a significant, positive effect from receiving an SEP from the online, self-service tool. Hispanic students who received an online SEP were $180 \%$ more likely to graduate than those Hispanic students who did not. Additionally, attending an orientation workshop had a significantly negative effect on completion for Hispanic students. Hispanic students who attended an orientation workshop were more than $40 \%$ less likely to graduate than Hispanic students who did not attend the orientation workshop. While this finding was also present in the overall sample, it does raise concerns about the kind of message that students receive when attending an orientation, and whether that message influences students to later drop out. 
Table 4.4

Logistic Regression Analysis Predicting Completion of Educational Goal, by Ethnicity

\begin{tabular}{|c|c|c|c|c|c|c|}
\hline \multirow{2}{*}{ Predictor } & \multicolumn{2}{|c|}{ White $(N=2,787)$} & \multicolumn{2}{|c|}{ Hispanic $(N=1,448)$} & \multicolumn{2}{|c|}{ African-American $(N=1,038)$} \\
\hline & OR & $95 \% \mathrm{CI}$ & $O R$ & $95 \% \mathrm{CI}$ & $O R$ & $95 \% \mathrm{CI}$ \\
\hline SEP (Counselor) & $1.698 * *$ & {$[1.241,2.324]$} & $2.255^{* * *}$ & {$[1.493,3.407]$} & $1.881^{*}$ & {$[1.036,3.417]$} \\
\hline SEP (Online) & .713 & {$[0.287,1.772]$} & $2.801 *$ & {$[1.250,6.274]$} & 2.271 & {$[0.705,7.314]$} \\
\hline Orientation Workshop & .952 & {$[0.702,1.290]$} & $.580 *$ & {$[0.352,0.957]$} & .749 & {$[0.343,1.632]$} \\
\hline Online Orientation & .642 & {$[0.160,2.578]$} & .861 & {$[0.138,5.357]$} & .000 & \\
\hline Assessment & $1.444^{*}$ & {$[1.052,1.983]$} & .946 & {$[0.569,1.574]$} & .656 & {$[0.319,1.352]$} \\
\hline Counseling & $1.651^{* * *}$ & {$[1.503,1.815]$} & $1.367 * * *$ & {$[1.199,1.559]$} & $1.509 * * *$ & {$[1.267,1.798]$} \\
\hline Declared Goal (Complete) & .802 & {$[0.595,1.081]$} & .788 & {$[0.512,1.214]$} & .854 & {$[0.462,1.580]$} \\
\hline Declared Goal (Other) & .807 & {$[0.485,1.343]$} & .566 & {$[0.306,1.046]$} & 1.200 & {$[0.502,2.869]$} \\
\hline Declared Major & $1.701^{* * *}$ & {$[1.273,2.274]$} & .779 & {$[0.513,1.183]$} & 1.718 & {$[0.867,3.404]$} \\
\hline Full-Time & $6.273 * * *$ & {$[4.213,9.340]$} & $9.775 * * *$ & {$[5.064,18.870]$} & $6.505 * * *$ & {$[2.535,16.696]$} \\
\hline Persistence & $1.606 * * *$ & {$[1.522,1.694]$} & $1.740 * * *$ & {$[1.610,1.881]$} & $1.761 * * *$ & {$[1.585,1.956]$} \\
\hline Financial Aid & .794 & {$[0.577,1.091]$} & .726 & {$[0.484,1.090]$} & .602 & {$[0.339,1.069]$} \\
\hline Disabled & .612 & {$[0.345,1.087]$} & .625 & {$[0.207,1.893]$} & .453 & {$[0.146,1.410]$} \\
\hline
\end{tabular}

$* \mathrm{p}<.05, * * \mathrm{p}<.01, * * * \mathrm{p}<.001$

$\begin{array}{llll}\text { Likelihood Ratio (Chi-Squared }) & .000 & .000 & .000 \\ \text { Cox \& Snell R } & .373 & .410 & .296 \\ \text { Nagelkerke R } & .573 & .633 & .569 \\ \text { Percent Correct } & .878 & .892 & .955\end{array}$

Note: $O R=$ odds ratio $; \mathrm{CI}=$ confidence interval 
Students with low socioeconomic status (as indicated by receipt of need-based financial aid) were different from students with high socioeconomic status in a few respects. First, high-SES students who attended orientation were actually less likely to complete than those students who did not attend orientation. This finding did not extend to students in the low-SES group, for whom attendance at orientation had no statistically significant effect. For the high-SES group, assessment and declaration of a major at initial enrollment significantly predicted completion, but neither of these had a statistically significant effect for the low-SES group. The insignificance of assessment may relate to the fact that low-SES students were more likely to take the placement test than high-SES students ( $70 \%$, versus $57 \%$ of high-SES students). Furthermore, $52 \%$ of low-SES students tested 3 or more levels below transfer-level math and $36 \%$ tested 2 or more levels below transfer-level English, compared with $41 \%$ and $26 \%$ of the high-SES group. It is possible that students for whom assessment predicted their successful completion were those that tested into transfer-level courses or higher levels of basic skills classes. Since the low-SES students were more likely to test into basic skills classes, they were less likely to see this benefit from the placement test.

The one uniquely significant factor for low-SES students was development of an SEP using the online degree-planning tool; low-SES students who used this service were more than twice as likely to complete than their counterparts who did not use this service. All other significant predictors of completion for the low-SES group were 
shared with the high-SES group: receipt of an SEP from a counselor ( $87 \%$ more likely), meeting with a counselor ( $40 \%$ more likely), full-time status (over 7 times more likely), and persistence, which all significantly improved the students' likelihood of completing.

Table 4.5

Logistic Regression Analysis Predicting Completion of Educational Goal, by Socioeconomic Status

\begin{tabular}{|c|c|c|c|c|}
\hline \multirow{2}{*}{ Predictor } & \multicolumn{2}{|c|}{ High SES $(N=5,544)$} & \multicolumn{2}{|c|}{ Low $\operatorname{SES}(N=2,185)$} \\
\hline & $O R$ & $95 \% \mathrm{CI}$ & $O R$ & $95 \% \mathrm{CI}$ \\
\hline SEP (Counselor) & $1.475^{* *}$ & {$[1.166,1.865]$} & $1.869 * * *$ & {$[1.385,2.522]$} \\
\hline SEP (Online) & 1.313 & {$[0.753,2.291]$} & $2.150^{*}$ & {$[1.100,4.205]$} \\
\hline Orientation Workshop & $.717^{* *}$ & {$[0.563,0.914]$} & .903 & {$[0.622,1.310]$} \\
\hline Online Orientation & .885 & {$[0.344,2.279]$} & .302 & {$[0.076,1.194]$} \\
\hline Assessment & $1.580^{* * *}$ & {$[1.239,2.016]$} & .884 & {$[0.608,1.287]$} \\
\hline Counseling & $1.705 * * *$ & {$[1.591,1.827]$} & $1.404 * * *$ & {$[1.286,1.534]$} \\
\hline Declared Goal (Comp.) & 1.057 & {$[0.854,1.308]$} & 1.043 & {$[0.766,1.421]$} \\
\hline Declared Goal (Other) & .899 & {$[0.621,1.302]$} & 698 & {$[0.428,1.136]$} \\
\hline Declared Major & $1.538 * * *$ & {$[1.239,1.910]$} & 1.309 & {$[0.940,1.824]$} \\
\hline Full-Time & $7.625 * * *$ & {$[5.620,10.345]$} & $7.429 * * *$ & {$[4.572,12.072]$} \\
\hline Persistence & $1.649 * * *$ & {$[1.584,1.716]$} & $1.682 * * *$ & {$[1.583,1.788]$} \\
\hline Disabled & $.420 * *$ & {$[0.247,0.715]$} & $.511^{*}$ & {$[0.275,0.949]$} \\
\hline Hispanic & .815 & {$[0.612,1.086]$} & .753 & {$[0.501,1.131]$} \\
\hline African-American & $.478 * *$ & {$[0.306,0.747]$} & $.349 * * *$ & {$[0.227,0.537]$} \\
\hline Asian & 1.183 & {$[0.908,1.541]$} & $1.568^{*}$ & {$[1.030,2.386]$} \\
\hline Multi-Ethnic & $.599 *$ & {$[0.371,0.966]$} & .823 & {$[0.454,1.493]$} \\
\hline Other Ethnicity & $1.388 *$ & {$[1.049,1.838]$} & 1.340 & {$[0.744,2.415]$} \\
\hline \multicolumn{5}{|c|}{$* p<.05^{* *} p<.01 * * * p<.001$} \\
\hline $\begin{array}{l}\text { Likelihood Ratio } \\
\text { (Chi-Squared) }\end{array}$ & .000 & & .000 & \\
\hline Cox \& Snell $\mathrm{R}^{2}$ & .413 & & .400 & \\
\hline Nagelkerke $\mathrm{R}^{2}$ & .625 & & .625 & \\
\hline Percent Correct & .884 & & .875 & \\
\hline
\end{tabular}

Note: $O R=$ odds ratio $; \mathrm{CI}=$ confidence interval; 
Students with disabilities were different from their non-disabled peers in a few unique ways. First, while non-disabled students who attended orientation were less likely to complete than students who did not attend orientation, orientation attendance had no significant impact on students with disabilities. Similarly, assessment and declaration of a major were significant predictors of completion for non-disabled students, but students with disabilities did not see a statistically significant benefit from these services. Follow-up analysis indicated that students with disabilities are significantly more likely to take the placement test $(75 \%$, versus $60 \%$ of non-disabled students) and $68 \%$ of students with disabilities tested 3 or more levels below transferlevel math and $52 \%$ tested 2 or more levels below transfer-level English, compared with $52 \%$ and $36 \%$ of non-disabled students.

The most unexpected finding for students with disabilities is in the area of declaring an educational goal of something other than completion of a degree, certificate, or transfer requirements. For non-disabled students, specifying an educational goal, either one that indicated a desire to complete a degree, certificate or transfer, or a non-completion-oriented goal, had no statistically significant impact on their likelihood of completing. However, students with disabilities who declared a noncompletion oriented goal were, in fact, over 7 times more likely to complete than those who declared a different educational goal or did not indicate an educational goal. 
Table 4.6

Logistic Regression Analysis Predicting Completion of Educational Goal, by Disability Status

\begin{tabular}{l|cc|cc}
\hline \multirow{2}{*}{ Predictor } & \multicolumn{2}{|c|}{ Non Disabled $(N=7,418)$} & \multicolumn{2}{c}{ Disabled $(N=311)$} \\
& OR & $95 \%$ CI & OR & $95 \%$ CI \\
\hline SEP (Counselor) & $1.567 * * *$ & {$[1.300,1.888]$} & $8.643 * *$ & {$[2.471,30.229]$} \\
SEP (Online) & 1.503 & {$[0.967,2.337]$} & $8.529 *$ & {$[1.190,61.111]$} \\
Orientation Workshop & $.753^{* *}$ & {$[0.614,0.925]$} & .793 & {$[0.205,3.073]$} \\
Online Orientation & .621 & {$[0.284,1.360]$} & 1.307 & {$[0.022,78.001]$} \\
Assessment & $1.362^{* *}$ & {$[1.109,1.673]$} & 1.640 & {$[0.269,9.998]$} \\
Counseling & $1.595^{* * *}$ & {$[1.507,1.687]$} & $2.089 * * *$ & {$[1.546,2.823]$} \\
Declared Goal (Comp.) & 1.051 & {$[0.881,1.254]$} & 1.675 & {$[0.567,4.951]$} \\
Declared Goal (Other) & .746 & {$[0.551,1.011]$} & $7.091 *$ & {$[1.271,39.549]$} \\
Declared Major & $1.453^{* * *}$ & {$[1.212,1.741]$} & 1.147 & {$[0.372,3.533]$} \\
Full-Time & $7.224 * * *$ & {$[5.574,9.361]$} & $112.375 * * *$ & {$[16.030,787.796]$} \\
Persistence & $1.665^{* * *}$ & {$[1.609,1.722]$} & $1.777^{* * *}$ & {$[1.446,2.184]$} \\
Financial Aid & $.786^{*}$ & {$[0.652,0.947]$} & .572 & {$[0.199,1.648]$} \\
Hispanic & .798 & {$[0.630,1.011]$} & .359 & {$[0.077,1.664]$} \\
African-American & $.393^{* * *}$ & {$[0.288,0.535]$} & $.101 * *$ & {$[0.021,0.487]$} \\
Asian & $1.312^{*}$ & {$[1.048,1.644]$} & .595 & {$[0.132,2.676]$} \\
Multi-Ethnic & .745 & {$[0.513,1.081]$} & $.080^{* *}$ & {$[0.009,0.735]$} \\
Other Ethnicity & $1.521^{* *}$ & {$[1.186,1.951]$} & .380 & {$[0.077,1.876]$} \\
\hline
\end{tabular}

$* p<.05 * * p<.01 * * * p<.001$

\begin{tabular}{|c|c|c|}
\hline $\begin{array}{l}\text { Likelihood Ratio } \\
\text { (Chi-Squared) }\end{array}$ & .000 & .000 \\
\hline Cox \& Snell R 2 & .408 & .460 \\
\hline Nagelkerke $\mathrm{R}^{2}$ & .613 & .708 \\
\hline Percent Correct & .880 & .80 \\
\hline
\end{tabular}

Note: $O R=$ odds ratio $\mathrm{CI}=$ confidence interval

All other significant predictors of completion for students with disabilities were shared with the non-disabled group: receipt of an SEP from a counselor, meeting with a counselor, full-time status, and persistence, which all significantly improved the 
students' likelihood of completing. It is important to note that the effect sizes for several of these variables, including receipt of an SEP and full-time status are extremely large, especially relative to the effect of these variables for the other underserved groups. This may reflect the fact that there was a much smaller sample of students with disabilities, compared to the sample size of the other underserved groups. This scenario generally means that outlier cases have a more significant impact on the results. While the sample size was large enough to ensure sufficient statistical power, smaller sample sizes do have a higher probability likelihood of a type I error (failure to reject the null hypothesis). As such, it is likely that while these factors do positively and significantly predict the outcome of completion for students with disabilities, in reality the effect is likely not as great as the results suggest.

\section{Research Question 3}

The logistic regression analysis conducted to answer the second research question was also used to answer the third research question: "Is there a pattern or combination of services that is more likely to lead to successful outcomes for students from certain underserved groups (Hispanic, African-American, low socioeconomic status, disabled)?" In general, the findings were consistent across groups, with most of the same variables appearing significantly positive in most or all groups.

Hispanic students are more likely to complete if they receive an SEP, either from a counselor or from using the online self-service degree-planning tool. They are 
also more likely to complete if they visit a counselor, attend full-time, and persist from one term to the next without stopping out. Of these behaviors, the most significant effects resulted from enrolling full-time and receiving an SEP from the online degreeplanning tool.

African-American students are more likely to complete if they see a counselor, receive an SEP from a counselor, enroll full time, or persist from one term to the next without stopping out. Of these, the most significant impacts came from enrolling fulltime and receiving an SEP from a counselor.

Low-socioeconomic students are more likely to complete if they receive an SEP, either from a counselor or from using the online self-service degree-planning tool. They are also more likely to complete if they visit a counselor, attend full-time, and persist from one term to the next without stopping out. Of these behaviors, the most significant impacts resulted from enrolling full-time and receiving an SEP from the online degreeplanning tool.

Students with disabilities are more likely to complete if they receive an SEP, either from a counselor or using the online, self-service degree-planning tool. They also benefitted from visiting a counselor, enrolling full-time, and persisting from one term to the next without stopping out. Of these behaviors, the most significant impacts resulted from enrolling full-time and receiving an SEP from a counselor. 


\section{Summary}

This quantitative study examined the effects of services mandated by the Student Success Act, as well as other academic factors of interest, on the completion of an educational goal for students enrolled in the CCCCD for the first time in the 2008-09 academic year. The study was guided by three research questions and informed by archival student record data supplied by the CCCCD Office of Institutional Research. Logistic regression analysis was employed in order to isolate factors predictive of completion of an educational goal.

This study uncovered several statistically significant predictors of completion. For the overall analysis, which compared students in the overall sample who completed an educational goal with those who did not, seven significant predictors of completion emerged. These included (1) receipt of an SEP from a counselor, (2) receipt of an SEP from the online, self-service degree planning tool, (3) participation in assessment testing, (4) visiting a counselor, (5) declaring a major at the time of application, (6) fulltime enrollment, and (7) persistence. The secondary analyses examined subsets of the sample from various identified underrepresented groups; these analyses also identified a number of significant predictors of completion. For Hispanic students, there were five statistically significant predictors of completion: (1) receipt of an SEP from a counselor, (2) receipt of an SEP from the online, self-service degree planning tool, (3) visiting a counselor, (4) full-time enrollment, and (5) persistence. For African-American students, 
there were statistically significant predictors of completion: (1) receipt of an SEP from a counselor, (2) visiting a counselor, (3) full-time enrollment, and (4) persistence. For students with low-socioeconomic status, there were five statistically significant predictors of completion: (1) receipt of an SEP from a counselor, (2) receipt of an SEP from the online, self-service degree planning tool, (3) visiting a counselor, (4) full-time enrollment, and (5) persistence. For students with disabilities, there were five statistically significant predictors of completion: (1) receipt of an SEP from a counselor, (2) receipt of an SEP from the online, self-service degree planning tool, (3) visiting a counselor, (4) declaring a non-completion-oriented educational goal, (5) full-time enrollment, and (6) persistence. These findings provide useful information for the CCCCD in terms of how to promote successful outcomes for their students.

In the next chapter, these findings are discussed in the context of the literature and interpreted further in the context of the CCCCD. Additionally, chapter five will present the implications of these findings for practitioners and educational leaders in the CCCCD, as well as informed recommendations for the district. 


\section{Chapter Five: Discussion and Recommendations}

\section{Overview}

The purpose of this study was to examine the effects of academic factors, student characteristics, and services mandated by the Student Success Act on the completion rates of students who enrolled in the Contra Costa Community College District for the first time in the 2008-09 academic year. This study used the definition of completion used by the California Community College Chancellor's Office, which includes completion of a degree, certificate, or attainment of transfer-prepared status.

This study was grounded in Tinto's (1975) Student Integration Theory, which posits that college students are more successful when they become socially integrated into their college community, and that institutions can help develop this integration by connecting with students early and providing support services to facilitate a smooth transition into the college environment. Three research questions guided this study:

1. Which of the support services mandated by the Student Success Act are most predictive of successful outcomes for students in the Contra Costa Community College District (CCCCD)?

2. How do the relationships between students' utilization of support services and their educational outcomes differ among students from identified underrepresented backgrounds (Hispanic, African-American, low socioeconomic status, disabled)? 
3. Is there a pattern or combination of services that is more likely to lead to successful outcomes for students from certain underserved groups (Hispanic, African-American, low socioeconomic status, disabled)?

Using SPSS, a logistic regression model was constructed to identify factors predictive of student completion, both for the overall sample and the identified subpopulations of interest. Results of the analysis identified eight variables as statistically significant predictors of completion for one or more groups.

\section{Interpretation of Findings}

\section{Universally Significant Findings}

Four factors emerged as statistically significant predictors of completion across all groups. These factors include receipt of an SEP from a counselor, one or more visits to a counselor, full-time enrollment, and persistence from one term to the next without stopping out. Of these findings, receipt of an SEP and visiting a counselor are both services mandated by the Student Success Act.

The finding that receipt of an SEP positively predicts students' completion supports an emerging body of literature regarding the importance of providing students with clear pathways to complete their educational goals. Furthermore, for nearly all groups, receipt of an SEP from a counselor was second only to full-time enrollment as the factor that has the greatest impact on students' likelihood of completion. These findings support the Student Success Act's emphasis on SEPs. It is important to note 
that both SEP variables - SEP from a counselor and SEP from the online, self-service degree-planning tool - were both consistently significant predictors of student completion. Receipt of an SEP from a counselor was significant across all groups, and online SEP was significant across all groups except for African-American students. This is an important finding as CCCCD continues to develop and extend its online degree planning tools.

The finding that visiting a counselor positively predicts students' completion is unsurprising and corroborates a broad body of literature on the importance of counseling and advising in promoting students' success. Counselors have many roles in supporting students' success, including helping students identify their educational goals, planning students' courses, and advising on strategies for being a more successful student. To the extent possible, CCCCD should prioritize counseling services and ensure that services are structured in a way that as many students as possible are aware of and can take advantage of counseling services. Additionally, it may be helpful to interpret this finding alongside the finding that SEPs have a positive impact on student completion rates, regardless of whether the SEP comes from a counselor or online. It may be worth investigating how much added benefit results from having a counselor develop a student's SEP. It is worth considering whether counselors' time is better spent addressing a wider variety of student needs than just educational planning. 
The findings regarding full-time enrollment and term-to-term persistence are consistent with literature regarding behaviors of successful students. The literature has shown that full-time enrollment provides additional opportunities for student engagement and academic integration (Center for Community College Student Engagement, 2015). Furthermore, for many students, full-time enrollment demonstrates a level of commitment to pursuing their educational goal. This is not to say that part time students are not serious about pursuing their educational goals; rather, full-time enrollment may be a proxy for motivational factors that are not directly measured in this study. As previously stated, full-time enrollment is not a luxury that all community college students can afford, however, as recommended by the Student Success Task Force, institutions ought to inform students about the positive effects of enrolling fulltime and make efforts to educate students about financial aid and other resources that can help them to attend full time.

It is important to note that while persistence might appear to be a tautological variable, given that a failure to persist may simply reflect that a student has dropped out, the data do not support this theory. Of the 3,935 students in the sample who stopped out for one or more terms, $40 \%$ went on to complete an educational goal. The finding regarding persistence is that students who maintain consistent enrollment for a longer period are more likely to complete an educational goal than students who stop out early. When examining students who stopped out, for each additional term that students 
persisted, students were more likely to re-enroll and more likely to eventually complete an educational goal. One theory for this finding is that the longer students persist, the more academically and socially integrated they become with the institution, and the better able they are to recover from taking a semester off. However, this finding may alternatively indicate that students who stop out early do so with less of an intention of returning, perhaps due to a failure to establish connections within the institution, or due to an inability to recover from negative experiences early in their educational career. This interpretation may reinforce the need for early alert programs that identify students who are at-risk early in their educational career and help provide the support they need to get on track.

\section{Narrowly Significant Findings}

Two factors - placement testing and declaring a major at initial enrollment were significant for the overall population, but were insignificant across all of the identified underrepresented groups. This finding regarding placement testing may be a cause for concern, given that the Student Success Act now mandates that students participate in this service. However, some important considerations may dispel this concern. First, the Student Success Act makes an effort to differentiate between "assessment" and "placement testing." There are ways that students can meet the assessment requirement without taking a placement test. The Student Success Act encourages community colleges to accept students' results on the Early Assessment 
Program test - which the California State University system uses to determine student eligibility for college level coursework, and juniors at most California high schools take. Some community colleges already accepted this as a form of placement before the Student Success Act, and given its widespread use by California high schools, it may serve to expand access to college-level courses. Second, one of the recommendations of the Student Success Task Force that has been taken up alongside SSSP implementation is the use of alternate measures of student achievement. The Multiple Measures Assessment Project (MMAP) has developed a research-based algorithm that utilizes students' high school transcript information to assess their appropriate placement in math and English. Extant research on multiple measures assessment suggests that this approach will result in more accurate placements, particularly for students from disadvantaged backgrounds (Ngo \& Kwon, 2015). Finally, it is important to note the limitations of how the placement testing variable was operationalized in this study. This variable indicates whether students took one or more subtests of the placement test, without considering the results of this test. Given that the placement test was not required at the time of this study, this variable may say more about the students who took the placement test, and why. Prior to the Student Success Act, students were only required to take a placement test if they wanted to take English or math courses, or in some cases to take courses with an English or math prerequisite. Given that these courses are requirements of obtaining a degree or transferring, it may be that for some 
students, taking a placement test is a proxy for a student's educational goal, distinguishing students who seriously plan to complete a degree or transfer from those students who are still identifying their goals. For all of these reasons, there should not be any concern that requiring students to take a placement test will negatively affect their likelihood of completing.

Like placement testing, declaring a major at initial enrollment was only a significant factor for the overall population, and insignificant for all identified underrepresented groups. This suggests that students from underrepresented backgrounds may change their goals over time. Perhaps some students who came in with an undeclared major were able to clarify their goal after enrolling and later went on to complete it. Perhaps other students came in with a goal, but after attending for a few semesters, learned that they could best accomplish their goal at a different college, or decided that their career goal did not require a degree or certificate after all. Further research might explore the differences in students' incoming goals and majors, and how these goals are influenced during a student's educational journey.

\section{Unexpected Findings}

The finding that participation in orientation has either a neutral or negative impact on students' likelihood of completion is noteworthy. This finding is somewhat unexpected, given that orientation is one of the SSSP mandated services, and the hypothesis behind mandating this service is that orientation attendance will make 
students more likely to succeed. The findings of this study do not support that hypothesis, which is noteworthy. To some extent, the finding that the orientation offered by CCCCD has no impact on student completion is unsurprising. While there is a significant body of literature pointing to the effectiveness of orientation in increasing students' success, there are significant differences between how orientation is defined in this literature, and how it has been implemented by the CCCCD. Given that much of the positive impact of orientation stems from its ability to foster a sense of social integration with the institution (Pascarella et al., 1986), it is hard to build much integration within a three-hour lecture-style orientation. This concept is also illustrated by the finding that online orientation was an insignificant factor across all groups, which makes sense given the challenges in developing social integration in an online setting. One might conclude that the best possible outcome of orientation is simply to raise students' awareness of the counseling and educational planning services that are available to them, given that these services have such a positive impact on student outcomes.

The finding that attending an orientation workshop negatively predicted the likelihood of completion for the overall population and Hispanic students is a cause for concern. This finding suggests that orientation may not currently be a service that welcomes students into a supportive and encouraging college environment, like the vision for SSSP services would suggest. Rather, this finding suggests that college 
orientation may be either directly or indirectly serving as a tool to weed out students. While this portrayal of orientation, or at least the stereotype thereof, is pervasive at highly selective institutions, which warn incoming students that many of their peers will not make it to graduation, it is troubling to think that orientation for community college students communicates this same message. Such a message seems to contradict the narrative that community colleges exist to provide open access to higher education, regardless of students' background and level of preparedness.

It is worth pointing out an interesting finding regarding orientation from the Center for Community College Student Engagement: for students who did not place into developmental coursework, attending an orientation session increased their likelihood of persisting both to the upcoming Spring semester and to the following Fall semester (Center for Community College Student Engagement, 2014). What is noteworthy is that this finding did not extend to students who did test into developmental coursework, which may suggest that a non-trivial number of developmental students drop out after attending an orientation. Given similar research that incoming community college students often enter with unrealistic understandings of how long it will take to complete their educational goals (Sanchez, 2012), it is possible that some students find orientation to be a dose of reality that leads them to consider dropping out. 
Another possible theory concerns research that many students come to college with the belief that they do not belong in the college environment, and these students are highly susceptible to messages and attitudes that reinforce this belief (Center for Community College Student Engagement, 2015). It may be that students like this attend an orientation and do not feel welcomed and encouraged to integrate into the college environment. Instead, they may be subject to messages that undermine this sense of social and academic integration, like the aforementioned warnings of failure that characterize orientation at some elite institutions. Instead, these kinds of messages would likely cause students to disengage from the college community and eventually drop out.

Additional research should certainly explore the relationship between orientation attendance and failure to complete one's educational goal. Practitioners should consider examining the content of orientation sessions and how this content is communicated to students. A qualitative research approach could also explore students' perceptions of college before and after attending an orientation session, to identify what kind of message students take away from orientation. It is equally important to examine the effect and experience of orientation for students from a variety of backgrounds. As the findings of this study suggest, students from different backgrounds may experience orientation differently, with some students experiencing a negative effect while others do not. 


\section{Limitations}

This study has several limitations that must be considered when interpreting its findings. The first category of limitations concerns internal validity and research design. First, the nature of a quantitative research design is that it limits the types of conclusions that one can draw from the study's findings. Questions of why students chose to visit a counselor or why they chose not to persist cannot be addressed using a quantitative methodology, and as such, are outside of the scope of this study. Second, the use of raw data from the CCCCD student information system limits the type of variables that were available for use in this study. Many other variables also play a role in students' likelihood of completion. These can include academic factors, such as the courses and instructors that students experienced, and non-academic factors, such as whether or not students also worked while attending school. As such, there are alternative explanations for whether or not students completed an educational goal, beyond the variables identified in this study. Finally, because community college students attend for many different reasons, including reasons that change during the course of a student's educational career, there is a degree of error with the outcome variable of completion of a degree, certificate, or transfer-prepared status. This outcome does not account for students who initially enrolled in the CCCCD and subsequently transferred to a different college before attaining transfer-prepared status. These students are considered "failures" in this study, even if they went on to complete their educational goal 
elsewhere. Furthermore, because transfer-prepared status is not the same thing as transferring, students who attained this outcome may not consider themselves to have completed an educational goal, especially if they are still enrolled. Some level of concern is mitigated by the fact that the outcome variable was operationalized to be consistent with the California community college system's definition of completion, but this limitation is still worth noting.

Another category of limitations is that of external validity and generalizability. As stated throughout this study, the primary audience of this case study is practitioners and leaders of the CCCCD; the degree to which the findings can be generalized to other community colleges is limited. An additional consideration for external validity is that for the cohort examined in this study, the mandates of the Student Success Act had not yet gone into effect. As such, there may be confounding variables that underlie the participation in SSSP services in this study, such as student motivation, which may not be generalized to students who participate in the services solely because of a mandate. Finally, the definitions of some of the service variables in this study have changed from the time that this cohort attended to the present. One of the colleges has changed the placement test it uses, and another is preparing to change its placement test in the next academic year. Additionally, the Student Success Act separated SEPs into two categories: comprehensive SEPs cover all requirements necessary to meet a student's educational goal, and abbreviated SEPs are only 1 or 2 semesters, typically designed for 
incoming students or students without a fully formed educational goal. The definition of SEP used in this study is that of a comprehensive SEP, but many of the SEPs in this study were developed prior to the revised criteria, so their actual comprehensiveness may vary. However, the remaining variables utilized in this study should not change significantly over time.

\section{Implications}

\section{Recent Changes at CCCCD}

In the past couple of years, as part of the requirements for implementing SSSP programs, the CCCCD colleges have engaged in the process of reviewing the SSSP services they provide. Each college has developed an SSSP plan outlining the services the colleges provide, including evaluations of the services and plans to improve and expand service delivery. In addition to each college's local efforts, the CCCCD has convened a handful of district-wide workgroups to coordinate district-wide initiatives and ensure consistency between the colleges. A number of changes to service provision have taken place as result of these efforts, many of which align with the findings and recommendations of this study.

One of the major changes has been to overhaul how the colleges provide orientation services. This multi-pronged effort included streamlining the content of information provided at orientations and shifting the majority of orientation offerings from in person workshops to online orientations on a new online platform. This change 
is consistent with this study's finding that students receive no benefit from attending orientations, and that many students may even receive a negative message from in person orientations. Participation in online orientation was not found to have the same negative effect that was identified for some students who attended in person orientation, so the shift to online orientation may help mitigate any of the negative influences that students perceive at an in person orientation. Given that the Student Success Act still requires that all new students participate in orientation, it makes sense to offer orientation in a way that satisfies the mandate without consuming a significant amount of staff resources. This allows college leaders to redirect resources to the SSSP services that are most impactful for students.

The colleges continue to offer the aforementioned "Super Saturday" orientation events, which are specifically designed for seniors graduating from local feeder high schools who are planning to attend one of the CCCCD colleges in the upcoming Fall semester. These events have been expanded to more than just a standard orientation and provide opportunities for social engagement and parent involvement. As such, they come closer to approximating the type of orientations described in the literature, and may help to foster students' sense of social and academic integration with the colleges. Students also leave these events with an abbreviated SEP, providing students with a roadmap for staying on track through their first few semesters. College counselors and 
outreach coordinators continue to evaluate these events to ensure that they are effectively meeting students' needs.

Additionally, the CCCCD has expanded implementation of online degree planning tools. Student Planning, the first tool the district implemented, was only introduced during the last 2 years of this study. Since then, its' features have expanded and more students have begun using it. Additionally, LMC has signed on as a pilot school for a new online degree planning system that will be implemented in the coming year. These efforts are promising in light of this study's finding that online SEPs had similarly positive effects on student completion as SEPs developed by a counselor. It is recommended that $\mathrm{CCCCD}$ continue to evaluate its online degree planning services to ensure that students receive the information they need to plan and complete their educational goals. Furthermore, as the online SEP tools continue to develop, the CCCCD colleges may want to consider using the online tools as an opportunity to reprioritize the work of counselors from development of SEPs to outreach for at-risk students and expanding counseling services to a broader range of students.

\section{Recommendations for Further Study}

The findings of this study contribute to the existing body of literature on student support services in community colleges. However, given how quickly service provision is changing within the California community colleges, and the importance of improving the outcomes of California community college students, there is still much that remains 
to be understood. There are a few areas where further research is needed to better understand some of the phenomena observed in this study.

Failure to Complete? More research is needed to understand why students do not complete a degree, certificate, or transfer requirements. While this study characterized such students as "failures," this may not accurately reflect these students" goals. In order to understand the impact of support services on students' completion of an educational goal, it is necessary to accurately define students' educational goals. Doing so will accurately account for students who never intended to complete, but may have still benefitted from the services and instruction they received.

Student Education Plans. Continue to explore the impact of student education plans on student outcomes, particularly as it relates to the modality in which students receive an SEP (from a counselor or through a self-service tool). Given the importance of visiting a counselor, is there an added benefit of seeing a counselor to develop an SEP, or is counselors' time better spent meeting with students for different reasons?

Orientation. Study the content of orientation workshops and students' perceptions thereof, to discover what students experience at these workshops that may influence them to drop out.

\section{Conclusions}

The findings of this study suggest that some of the services mandated by the Student Success Act do have a significant, positive effect on student completion of an 
educational goal for students in the Contra Costa Community College District. Both counseling and receipt of an SEP have a positive impact for all students, and placement testing has a limited positive impact for students who are not from underrepresented groups (African-American, Hispanic, low socioeconomic status, and disabled). These findings reinforce the importance of the SSSP mandated services and indicate that the $\mathrm{CCCCD}$ is on the right track with providing services to not only satisfy the mandates, but also help improve outcomes for their students. CCCCD leaders should continue to explore how the offer orientation services, in light of the finding that orientation has a neutral or even negative impact on student completion.

The findings of this study also suggest that there are some differences between underrepresented groups and their majority peers in terms of how SSSP services and other factors influence student completion. However, students from all underrepresented groups experience a significant, positive effect from participation in counseling, receipt of an SEP, full-time enrollment, and continuous enrollment. Based on these findings, it is recommended that CCCCD practitioners ensure that students from these underrepresented groups are aware of and have access to these services, are educated about the benefits of enrolling full-time, and have resources available to support their persistence at the beginning of their educational journey.

Based on these findings, it is recommended that CCCCD leaders prioritize directing resources toward counseling and SEPs in order to help promote the best 
outcomes for students. By implementing these recommendations, the CCCCD could begin to see higher rates of student completion across all demographic groups. Such action on the part of CCCCD leaders and practitioners will help ensure that more CCCCD students identify and achieve their goals. 


\section{References}

Academic Senate for California Community Colleges. (2010). ASCCC Basic Skills

Summary Report 2006 to 2009. Retrieved from http://www.cccbsi.org/Websites/ basicskills/Images/BSISummary\%20report_Final09.doc

Adelman, C. (2005). Moving into town -- and moving on: The community college in the lives of traditional-age students. Washington, DC: U.S. Department of Education. Retrieved from

https://www2.ed.gov/rschstat/research/pubs/comcollege/movingintotown.pdf

Bahr, P. (2008). Cooling Out in the Community College: What is the Effect of Academic Advising on Students' Chances of Success? Research in Higher Education, 49(8), 704-732. https://doi.org/10.1007/s11162-008-9100-0

Bahr, P. R. (2004). The rough and rocky road of remediation: Racial inequalities in postsecondary remedial mathematics (Ph.D.). University of California, Davis, United States -- California. Retrieved from http://search.proquest.com.jpllnet.sfsu.edu/dissertations/docview/305213971/abs tract/CE6844B51C644B9PQ/1

Belfield, C., \& Crosta, P. M. (2012). Predicting Success in College: The Importance of Placement Tests and High School Transcripts (CCRC Working Paper No. 42). New York: Columbia University, Teachers College, Community College Research Center. 
Beshears, J., Choi, J. J., Laibson, D., \& Madrian, B. C. (2008). How are Preferences Revealed? (Working Paper No. 13976). National Bureau of Economic Research. Retrieved from http://www.nber.org/papers/w13976

Borglum, T., \& Kubala, K. (2000). Academic and Social Integration of Community College Students: A Case Study. Community College Journal of Research and Practice, 24(7), 567-576. https://doi.org/10.1080/10668920050139712

Boroch, D., Fillpot, J., Hope, L., Johnstone, R., Mery, P., Serban, A., ... Gabriner, R. S. (2007). Basic Skills as a Foundation for Student Success in California Community Colleges. Research and Planning Group for California Community Colleges (RP Group). Retrieved from http://eric.ed.gov/?id=ED496117 California Community Colleges Chancellor's Office. (2012). Gov. Brown Signs Student Success Act of 2012 into Law, Ushering in Improvements at California Community Colleges [Press Release]. Retrieved from http://extranet.cccco.edu/Portals/1/SSSP/Matriculation/SB1456StudentSuccessA ctOf2012/PressReleaseSB1456StudentSuccessActOf2012SignedGov.pdf California Community Colleges Chancellor's Office. (2014). Student success and support program handbook. Retrieved from http://extranet.cccco.edu /Divisions/StudentServices/Matriculation/Handbook.aspx 
California Community Colleges Chancellor's Office. (2015, October 23). SSSP

Allocations. Retrieved June 25, 2016, from http://extranet.cccco.edu/Divisions/ StudentServices/Matriculation/Allocations.aspx

California Community Colleges Chancellor's Office. (2016). Student success scorecard metrics [Data file]. Retrieved from http://datamart.cccco.edu/App_Doc/Scorecard_Data_Mart_Specs.pdf

California Community Colleges Chancellor's Office. (n.d.). Methodology for College Profile Metrics. Retrieved from http://datamart.cccco.edu/App_Doc/ Scorecard_Data_Mart_Specs.pdf

California Community Colleges Chancellor's Office, Research, Analysis and Accountability Unit, Technology, Research and Information Systems Division. (2013). Development of the Chancellor's Office Scorecard Metrics. California Community Colleges Chancellor's Office. Retrieved from http://scorecard.cccco.edu/scorecarddocumentation.aspx

California Community Colleges, Student Success Task Force. (2011). Advancing student success in California Community Colleges: The recommendations of the California community colleges student success task force. Retrieved from http://californiacommunitycolleges.cccco.edu/ Portals/0/StudentSuccessTaskForce/SSTF_FinalReport_Web_010312.pdf 
Carey, K. (2008). Graduation Rate Watch: Making Minority Student Success a Priority. Washington, D.C.: Education Sector.

Center for Community College Student Engagement. (2014). A matter of degrees: Practices to pathways (High-impact practices for community college student success). Austin, TX: The University of Texas at Austin, Program in Higher Education Leadership.

Center for Community College Student Engagement. (2015). Engagement rising: A decade of CCSSE data shows improvements across the board. Austin, TX: The University of Texas at Austin, Program in Higher Education Leadership.

Cone, J. D., \& Foster, S. L. (2006). Dissertations and theses from start to finish: psychology and related fields (2nd ed). Washington, DC: American Psychological Association.

Dadgar, M., Venezia, A., Nodine, T., \& Bracco, K. R. (2013). Providing structured pathways to guide students toward completion. San Francisco: WestEd.

Deil-Amen, R. (2011). Socio-Academic Integrative Moments: Rethinking Academic and Social Integration Among Two-Year College Students in Career-Related Programs. Journal of Higher Education, 82(1), 54-91.

Denny, J. K., Nelson, D. G., \& Zhao, M. Q. (2012). Creating and Analyzing the Effectiveness of a Mathematics Placement Policy for New Freshmen. Primus : 
Problems, Resources, and Issues in Mathematics Undergraduate Studies, 22(3), 177-185.

Derby, D. C. (2007). Predicting Degree Completion: Examining the Interaction between Orientation Course Participation and Ethnic Background. Community College Journal of Research and Practice, 31(11), 883-894.

Derby, D. C., \& Smith, T. (2004). An orientation course and community college retention. Community College Journal of Research and Practice, 28(9), 763773. https://doi.org/10.1080/10668920390254771

Ellis-O’Quinn, A. (2012). An Ex Post Facto Study of First-Year Student Orientation as an Indicator of Student Success at a Community College. Inquiry, 17(1), 51-57.

Fowler, P. R., \& Boylan, H. R. (2010). Increasing Student Success and Retention: A Multidimensional Approach. Journal of Developmental Education, 34(2), 2-410.

Gantt, A. J. (2010). Graduation Rates of Students in Technical Programs at an Urban Community College. Community College Journal of Research and Practice, 34(3), 227-239.

Goomas, D. T. (2012). Closing the Gap: Merging Student Affairs, Advising and Registration. Community College Journal of Research and Practice, 36(1), 5961. 
Grubb, W. N., \& Gabriner, R. (2012). Basic Skills Education in Community Colleges: Inside and Outside of Classrooms. New York: Routledge.

Halpin, R. L. (1990). An application of the Tinto model to the analysis of freshman persistence in a community college. Community College Review, 17, 22-32. https://doi.org/10.1177/009155219001700405

Hollins, T. N., Jr. (2009). Examining the Impact of a Comprehensive Approach to Student Orientation. Inquiry, 14(1), 15-27.

Ifill, N., Radford, A. W., Wu, J., Cataldi, E. F., Wilson, D., \& Hill, J. (2016). Persistence and Attainment of 2011-12 First-Time Postsecondary Students After 3 Years (BPS: 12/14) (NCES 2016-401). U.S. Department of Education. Washington, DC: National Center for Education Statistics. Retrieved from http://nces.ed.gov/pubsearch

Jaggars, S. S., \& Fletcher, J. (2014). Redesigning the Student Intake and Information Provision Processes at a Large Comprehensive Community College (CCRC Working Paper No. 72). New York: Columbia University, Teachers College, Community College Research Center.

Jenkins, D., \& Cho, S.-W. (2013). Get With the Program ... and Finish It: Building Guided Pathways to Accelerate Student Completion. New Directions for Community Colleges, 2013(164), 27-35. https://doi.org/10.1002/cc.20078 
Johnstone, R. (2015). Guided pathways demystified: Exploring ten commonly asked questions about implementing guided pathways. National Center for Inquiry and Improvement. Retrieved from http://www.inquiry2improvement.com

Kurzweil, M., \& Wu, D. D. (2015). Building a Pathway to Student Success at Georgia State University. New York: Ithaka S+R. Retrieved from http://sr.ithaka.org/?p=221053

Mayo, T. (2013). First-Year Course Requirements and Retention for Community Colleges. Community College Journal of Research \& Practice, 37(10), 764768. https://doi.org/10.1080/10668921003723292

McKinney, L., \& Novak, H. (2013). The Relationship Between FAFSA Filing and Persistence Among First-Year Community College Students. Community College Review, 41(1), 63-85. https://doi.org/10.1177/0091552112469251

Medhanie, A. G., Dupuis, D. N., LeBeau, B., Harwell, M. R., \& Post, T. R. (2012). The Role of the ACCUPLACER Mathematics Placement Test on a Student's First College Mathematics Course. Educational and Psychological Measurement, 72(2), 332-351. https://doi.org/10.1177/0013164411417620

Myers, S. A. (2012). Community college counseling, student education plans, and educational outcomes: A quantitative analysis (Doctoral dissertation, San Francisco State University). Retrieved from https://diva.sfsu.edu/users/eddsfsu/courses/dissertations 
Ngo, F., \& Kwon, W. W. (2015). Using Multiple Measures to Make Math Placement Decisions: Implications for Access and Success in Community Colleges. Research in Higher Education, 56, 442-470. https://doi.org/10.1007/s11162$014-9352-9$

Nguyen, A., Hays, B., \& Wetstein, M. (2010). Showing Incoming Students the Campus Ropes: Predicting Student Persistence Using a Logistic Regression Model. Journal of Applied Research in the Community College, 18(1), 16-21.

Ornelas, A., \& Solorzano, D. (2004). Transfer conditions of latina/o community college students: A single institution case study. Community College Journal of Research \& Practice, 28(3), 233-248.

O’Toole, D. M., Stratton, L. S., \& Wetzel, J. N. (2003). A Longitudinal Analysis of the Frequency of Part-Time Enrollment and the Persistence of Students Who Enroll Part Time. Research in Higher Education, 44(5), 519.

Packard, B. W.-L., \& Jeffers, K. C. (2013). Advising and Progress in the Community College STEM Transfer Pathway. NACADA Journal, 33(2), 65-75. https://doi.org/10.12930/NACADA-13-015

Pascarella, E. T., Terenzini, P. T., \& Wolfle, L. M. (1986). Orientation to College and Freshman Year Persistence/Withdrawal Decisions. The Journal of Higher Education, 57(2), 155-175. https://doi.org/10.2307/1981479 
Perrine, R. M., \& Spain, J. W. (2008). Impact of a Pre-Semester College Orientation Program: Hidden Benefits? Journal of College Student Retention, 10(2), 155169.

Rodicio, L., Mayer, S., \& Jenkins, D. (2014). Strengthening Program Pathways Through Transformative Change. New Directions for Community Colleges, 2014(167), 63-72. https://doi.org/10.1002/cc.20111

Rodwell, G. (2014). Providing transparent information to empower students' decision making and develop institutional capacity. New Directions for Community Colleges, 167, 53-61.

Rueda, N. G., \& Sokolowski, C. (2004). Mathematics Placement Test: Helping Students Succeed. Mathematics Educator, 14(2), 27-33.

Ryan, M. G. (2013). Improving Retention and Academic Achievement for First-Time Students at a Two-Year College. Community College Journal of Research \& Practice, 37(2), 130-134. https://doi.org/10.1080/10668926.2012.715266

Sanchez, M. M. (2012). Aspirations, Barriers, and Transfer Opportunities for Latina and Latino Community College Students (Ph.D.). University of California, Los Angeles, United States -- California. Retrieved from http://search.proquest.com.jpllnet.sfsu.edu/dissertations/docview/1025744286/a bstract/8EEA9037A9FA4200PQ/2 
Scott-Clayton, J. (2011). The shapeless river: Does a lack of structure inhibit students' progress at community colleges? (Working Paper No. 25). New York: Columbia University, Teachers College, Community College Research Center.

Seymour-Campbell Matriculation Act, Cal. Educ. Code $§ 78210$ et seq. (1986).

Retrieved from http://leginfo.legislature.ca.gov/faces/codes.xhtml

Seymour-Campbell Student Success Act, Cal. Educ. Code $§ 78210$ et seq. (2012).

Retrieved from http://leginfo.legislature.ca.gov/faces/codes.xhtml

Shepler, D. K., \& Woosley, S. A. (2012). Understanding the Early Integration

Experiences of College Students with Disabilities. Journal of Postsecondary Education \& Disability, 25(1), 37-50.

Shulock, N., \& Moore, C. (2007). Rules of the game: How state policy creates barriers to degree completion and impedes student success in the California community colleges. Sacramento, CA: Institute for Higher Education Leadership \& Policy, Sacramento State University.

Skomsvold, P., Radford, A. W., \& Berkner, L. (2011). Six-year attainment, persistence, transfer, retention, and withdrawal rates of students who began postsecondary education in 2003-04 (NCES 2011-152). U.S. Department of Education. Washington, DC: National Center for Education Statistics.

Stuart, G. R., Rios-Aguilar, C., \& Deil-Amen, R. (2014). “How Much Economic Value Does My Credential Have?": Reformulating Tinto's Model to Study Students' 
Persistence in Community Colleges. Community College Review, 42(4), 327341. https://doi.org/10.1177/0091552114532519

Tinto, V. (1975). Dropout from Higher Education: A Theoretical Synthesis of Recent Research. Review of Educational Research, 45(1), 89-125.

Tinto, V. (1987). Leaving College: Rethinking the Causes and Cures of Student Attrition. Chicago: University Of Chicago Press.

Tinto, V. (1999). Taking Retention Seriously: Rethinking the First Year of College. NACADA Journal, 19(2), 5-9. https://doi.org/10.12930/0271-9517-19.2.5

Tversky, A., \& Simonson, I. (1993). Context-dependent preferences. Management Science, 39(10), 1179.

Venezia, A., Bracco, K. R., \& Nodine, T. (2010). One-shot deal? Students' perceptions of assessment and course placement in California's community colleges. San Francisco: WestEd.

Zeidenberg, M. (2012). Valuable Learning or "Spinning Their Wheels"? Understanding Excess Credits Earned by Community College Associate Degree Completers (CCRC Working Paper No. 44). New York: Columbia University, Teachers College, Community College Research Center. 